\title{
MODELO GRAVIMÉTRICO-MAGNÉTICO DO GRÁBEN DE PARANAGUÁ-PR, BRASIL
}

\author{
Luís Gustavo de Castro ${ }^{1}$, Francisco J.F. Ferreira² e Rodolfo José Angulo³ \\ Recebido em 22 maio, 2007 / Aceito em 12 setembro, 2008 \\ Received on May 22, 2007 / Accepted on September 12, 2008
}

\begin{abstract}
We study the Paranaguá Graben, which is part of the Cenozoic Rift System of southeastern Brazil. Specifically, it is considered a gravimetric-magnetic model of the top of the Precambrian basement under the Cenozoic sediments of the Paraná state coastal plain. We aim to identify the main structures of the Paranaguá Graben. We also evaluate the thickness of the sedimentary section and the Mesozoic basic intrusions in the basement. We use a regional geophysical survey that extends for more than $55 \mathrm{~km}$ of gravimetric profiles with $500 \mathrm{~m}$ of spacing between the stations and about $45 \mathrm{~km}$ of magnetic profiles with spacing of $25 \mathrm{~m}$. The geophysical profiles were located between Paranaguá Bay and the Saí-guaçú river outlet, both in the context of the central region of the Ponta Grossa Arch (PGA). Data were collected along NE-SW acquisition lines, perpendicularly to the principal trend of the PGA. We present a 2-D geologic model using on gravity and magnetic data. We incorporate prior knowledge about the basement depth provided by boreholes. The identification of gravity high was related to a basement uplifting (Canoas structural high). Contiguous gravity lows had been interpreted as structural lows and called Albatroz and Shangri-lá, whose maximum thickness of the sediments is $130 \mathrm{~m}$. The magnetic model allowed to estimate the thicknesses of the basic dykes and to calculate an average crustal extension of $27 \%$ related to $45 \mathrm{~km}$ of the magnetic profiles.
\end{abstract}

Keywords: Ponta Grossa Arch, Paraná state coast, Paranaguá Graben, gravimetric-magnetic model, crustal extension.

RESUMO. 0 objetivo deste trabalho é contribuir com o estudo do Gráben de Paranaguá, feição tectônica integrante do Sistema de Riftes Cenozóicos do Sudeste do Brasil. Especificamente, propõe-se um modelo gravimétrico-magnético do topo do embasamento Pré-Cambriano sob os sedimentos cenozóicos da planície costeira paranaense. Buscou-se identificar as estruturas principais e estimar a espessura da cobertura sedimentar e das intrusões básicas mesozóicas do embasamento. Para tanto foram realizados levantamentos geofísicos regionais, os quais totalizaram mais de 55 quilômetros de perfis gravimétricos com espaçamento de 500 metros entre as estações e cerca de 45 quilômetros de perfis magnéticos com medidas a cada 25 metros. Os perfis geofísicos, situados entre a Baía de Paranaguá e a desembocadura do rio Saí-guaçú, na região central do Arco de Ponta Grossa (APG), foram orientados na direção NE-SW, perpendicularmente à tendência principal do APG. A concepção do modelo 2-D foi baseada na modelagem dos dados gravimétricos e magnéticos e calibrada por registros de profundidade do embasamento derivados de poços tubulares. A identificação de um alto gravimétrico foi relacionada a um soerguimento do embasamento (Alto Estrutural de Canoas). Baixos gravimétricos contíguos foram interpretados como baixos estruturais e denominados Albatroz e Shangri-lá, cuja espessura máxima do preenchimento sedimentar é de 130 metros. 0 modelo magnético permitiu estimar as espessuras dos diques de diabásio e calcular uma extensão crustal próxima de 27\% relativamente aos 45 km de perfis magnéticos.

Palavras-chave: Arco de Ponta Grossa, litoral paranaense, Gráben de Paranaguá, modelo gravimétrico-magnético, extensão crustal.

\footnotetext{
$\overline{1}$ Laboratório de Pesquisas em Geofísica Aplicada, LPGA, Curso de Pós-Graduação em Geologia, Departamento de Geologia, Universidade Federal do Paraná, Centro Politécnico, Jardim das Américas, Caixa Postal 19045, 81531-980 Curitiba, PR, Brasil. Tel./Fax: (41) 3361-3132 - E-mail: Ig_bageo@hotmail.com

2Laboratório de Pesquisas em Geofísica Aplicada, LPGA, Curso de Pós-Graduação em Geologia, Departamento de Geologia, Universidade Federal do Paraná, Centro Politécnico, Jardim das Américas, Caixa Postal 19045, 81531-980 Curitiba, PR, Brasil. Tel./Fax: (41) 3361-3132 - E-mail: francisco.ferreira@ufpr.br

3 Laboratório de Estudos Costeiros, LECOST, Curso de Pós-Graduação em Geologia, Departamento de Geologia, Universidade Federal do Paraná, Centro Politécnico, Jardim das Américas, Caixa Postal 19001, 81531-980 Curitiba, PR, Brasil. Tel./Fax: (41) 3361-3135 - E-mail: angulo@ufpr.br
} 


\section{INTRODUÇÃo}

A região da planície costeira paranaense vem sendo estudada há mais de meio século por diversos autores. 0 mapa geológico do litoral paranaense, publicado por Bigarella (1946), constitui 0 marco inicial dos trabalhos de pesquisa na região. Em continuidade, podem ser destacados o mapa geológico da Baía de Guaratuba (Bigarella et al., 1957), as folhas geológicas na escala 1:70.000 publicadas pela Comissão da Carta Geológica do Estado do Paraná (Rivereau et al., 1968, 1969 a,b,c,d,e, 1970 apud Angulo, 2004) e o Mapa Geológico do Quaternário Costeiro dos Estados do Paraná e Santa Catarina, na escala 1:200.000 (Martin et al., 1988 apud Angulo, 1992). Mais recentemente destacamos contribuições como o Mapa do Cenozóico do Litoral do Estado do Paraná (Angulo, 2004) e as pesquisas sobre a estratigrafia e evolução das barreiras holocênicas paranaenses (Souza, 2005).

0 conhecimento das unidades do litoral paranaense e de suas relações estratigráficas constitui uma sólida base de dados a partir da qual é possível traçar a evolução dos processos de formação desta região do estado. Contudo, a falta de informações sobre a conformação do substrato dos sedimentos, constitui uma lacuna na sua história geológica. Em geral, a evolução do conhecimento geológico do embasamento é construída pela integração de informações diretas, derivadas de dados descritivos de poços, e indiretas baseadas em levantamentos geofísicos. Neste sentido, Souza (1995) e Souza et al. (1996), com base em levantamentos gravimétricos e magnetométricos, propuseram um modelo geológico do embasamento da planície costeira Cananéia Iguape, litoral sul do Estado de São Paulo. De forma semelhante, o presente estudo propõe um modelo gravimétrico-magnético da porção continental da planície costeira paranaense, controlado por dados de profundidade do topo do embasamento obtidos de poços.

\section{CARACTERIZAÇÃO DA ÁREA DE ESTUDO}

A área de estudo compreende a porção continental centro-sul da planície costeira do Estado do Paraná (Fig. 1), mais precisamente a faixa de ocupação limitada a Norte pela Baía de Paranaguá e ao Sul pela foz do rio Saí-guaçú. Abrange parte dos municípios de Pontal do Paraná, Matinhos e Guaratuba.

Zalán \& Oliveira (2005) apresentam na Figura 20 arcabouço estrutural regional do que denominaram Sistema de Riftes Cenozóicos do Sudeste do Brasil (SRCSB). Esta região foi anteriormente caracterizada como Sistema de Riftes da Serra do Mar (Almeida, 1976), ou ainda, conforme Riccomini (1991), Rifte Continental do Sudeste do Brasil (RCSB). Segundo Zalán \& Oliveira (2005), o SRCSB é dividido em quatro grandes riftes ou corredores de grábens: Paraíba do Sul, Ribeira, Litorâneo e Marítimo. 0 rifte Litorâneo engloba, de leste para oeste, os grábens da Barra de São João, Guanabara, Ubatuba, Santos, Ribeira do Iguape, Cananéia e Paranaguá. Este último (Fig. 2) envolve a planície costeira paranaense, objeto da presente pesquisa.

A Figura 3 mostra um perfil morfoestrutural dos grábens do Alto Ribeira e Paranaguá e da Bacia de Curitiba, indicando a área de estudo.

A região é caracterizada por uma alta densidade de intrusões mesozóicas, na forma de um cerrado enxame de diques de diabásio, com direção geral NW-SE, alojado no embasamento PréCambriano, cujas tendências estruturais se dispõem preferencialmente segundo a direção NE-SW. Na área de estudo (Fig. 4), 0 embasamento é recoberto por sedimentos quaternários costeiros (Fig. 5) e integra a região central do Arco de Ponta Grossa, a qual se reflete como um alto gravimétrico (Fig. 4), delimitada ao norte pelo Alinhamento São Jerônimo-Curiúva e ao sul pelo Alinhamento do Rio Alonzo (Ferreira, 1982 a,b).

Localmente, a geologia da área de estudo (Fig. 5), pode ser dividida em dois domínios principais: 0 das rochas do embasamento, juntamente com as intrusões básicas juro-cretáceas, e 0 dos sedimentos cenozóicos. A cobertura sedimentar cenozóica, por sua vez, é dividida em dois grandes grupos: um formado por sedimentos de origem continental (leques e cones aluviais, tálus, colúvios e sedimentos fluviais) e outro constituído por sedimentos de origem costeira (planície costeira com cordões litorâneos e sedimentos estuarinos). As idades variam desde 0 Mioceno Inferior até 0 Holoceno, incluindo os ambientes atuais de sedimentação (Angulo, 2004). Dentre os depósitos de sedimentos continentais são relacionados aqueles da Formação Alexandra, os associados a vertentes como cones e leques aluviais, depósitos de tálus e colúvios, vinculados a fluxos gravitacionais, e os de origem fluvial. Os sedimentos costeiros correspondem a dois sistemas deposicionais distintos. Um deles é relacionado à planície com cordões litorâneos, que inclui sedimentos de ambiente de face litoral (shore face), praia, dunas e brejos em depressões intercordões atuais (Angulo, 1992). 0 outro se refere aos estuários, com sedimentos paleoestuarinos caracterizando ambientes de maré e fundos rasos. Em ambientes atuais é possível identificar planícies de maré, fundos rasos e deltas de maré.

\section{MATERIAL E MÉTODOS}

Para o presente estudo utilizamos os métodos geofísicos gravimétrico e magnético, aliados a técnicas de posicionamento por receptores GPS (Global Positioning System). Todos os dados 


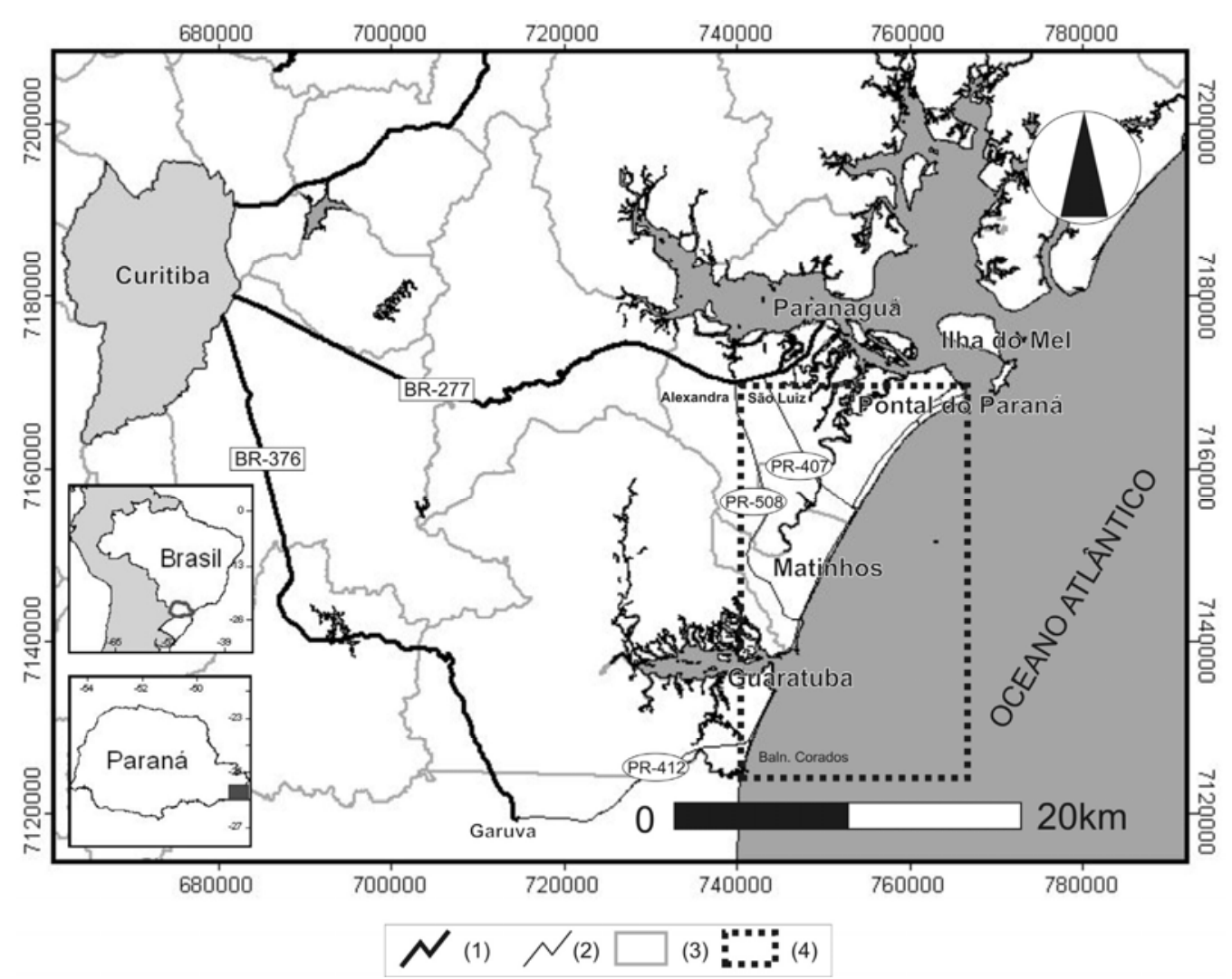

Figura 1 - Localização e acessos da área de estudo (retângulo pontilhado). (1) rodovias federais; (2) rodovias estaduais; (3) limites municipais; (4) área de estudo (modificado de Mineropar, 2001).

foram georreferenciados em Sistema de Informações Geográficas (SIG).

\section{Posicionamento das estações geofísicas}

0 posicionamento das estações geofísicas foi realizado com base em cartas topográficas na escala 1:50.000 (Diretoria de Serviço Geográfico - DSG e IBGE) e em dados planialtimétricos obtidos por receptores GPS, os quais foram utilizados tanto para a navegação quanto para 0 posicionamento das estações. Os dados altimétricos foram adquiridos com precisão horizontal nominal do receptor GPS de $0.005 \mathrm{~m} \pm$ 1 ppm e precisão vertical de $0.01 \mathrm{~m} \pm 2 \mathrm{ppm}$. As bases utilizadas como referências para 0 ajustamento foram às estações do Centro de Estudos do Mar (CEM), situada em Pontal do Sul-PR, e a do Centro Politécnico, localizada em Curitiba-PR, esta última pertencente à Rede Brasileira de Monitoramento Contínuo do Instituto Brasileiro de Geografia e Estatística (IBGE), ambas da Universidade Federal da Paraná (UFPR). Os espaçamentos das estações gravimétricas e magnetométricas foram de 500 e 25 metros, respectivamente.

\section{Levantamento e pré-processamento dos dados gravimétricos}

0 levantamento gravimétrico envolveu 111 estações, distribuídas ao longo de 55 quilômetros. As medidas da aceleração da gravidade foram adquiridas por um gravímetro digital modelo CG3 (Autograv, fabricação Scintrex, precisão nominal de $5 \mu \mathrm{Gal}$ ), simultaneamente ao posicionamento das estações e obtenção dos dados altimétricos, ao longo de estradas e ruas do litoral paranaense. 0 perfil foi realizado na direção NE-SW, aproximadamente paralelo à linha de costa, partindo do Centro de Estudos do Mar (CEM-UFPR), no Balneário de Pontal do Sul, até a foz do rio Saí-guaçú, na localidade de Barra do Saí (Fig. 6).

A primeira etapa do pré-processamento dos dados correspondeu ao cálculo das derivas estática e dinâmica, e da correção de maré, esta última realizada automaticamente pelo instrumento. Em seguida foram calculadas variações relativas de gravidade de cada estação, vinculadas à estação base. 0 valor absoluto de $\mathbf{g}$ na estação base foi somado às medidas relativas, obtendo-se, assim, os valores absolutos de $\mathbf{g}$ para cada estação. Em continuidade, realizamos as reduções Ar Livre e Bouguer. Ressaltamos 


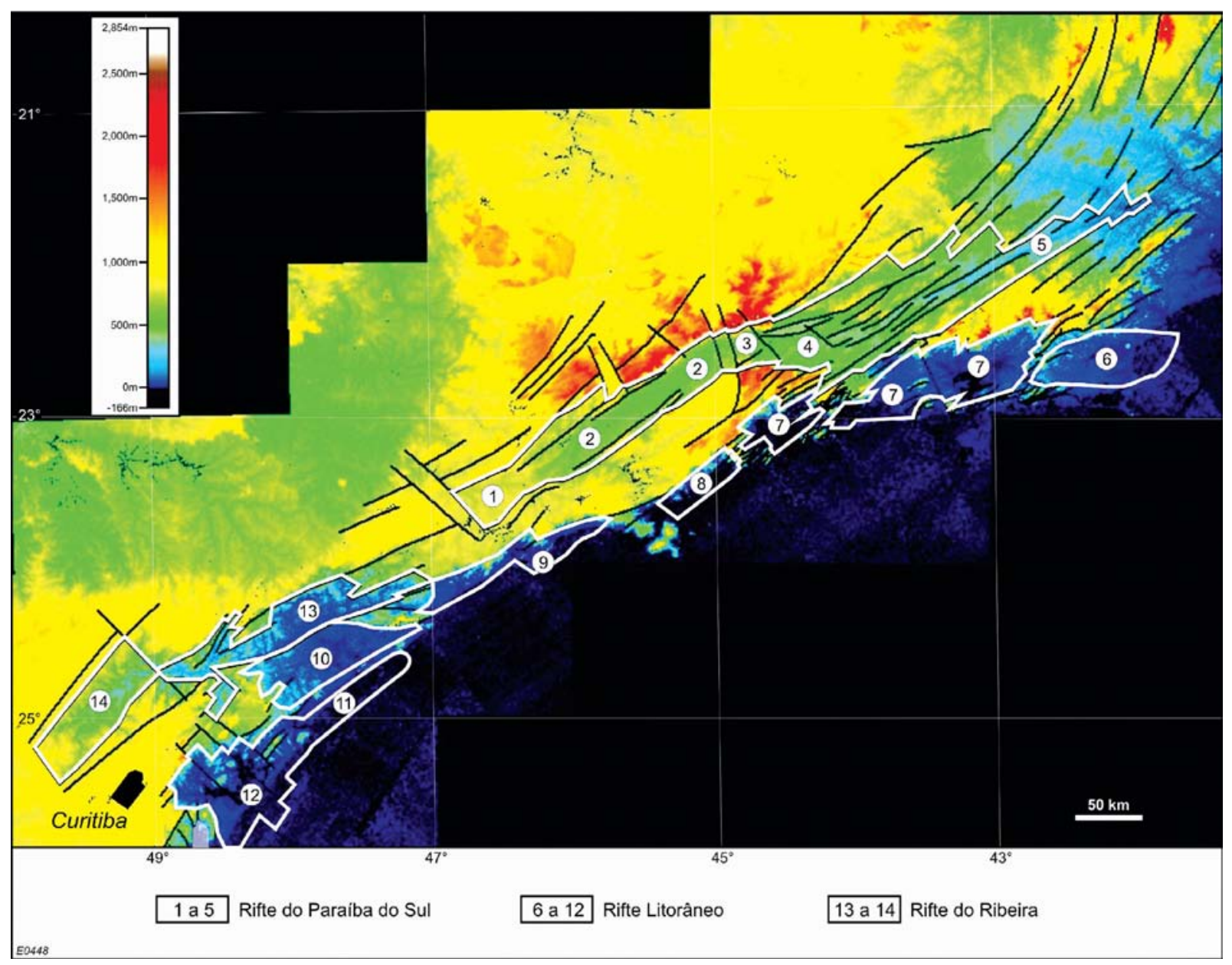

Figura 2 - Mapa topográfico do Sudeste do Brasil (SRTM/USGS, 2000) com o arcabouço estrutural regional do SRCSB interpretado. Números indicam grábens dentro dos riftes: Paraíba do Sul: (1) São Paulo; (2) Taubaté; (3) Queluz; (4) Resende-Volta Redonda; (5) Baixo Paraíba do Sul. Litorâneo: (6) Barra de São João; (7) Guanabara; (8) Ubatuba; (9) Santos; (10) Ribeira do Iguape; (11) Cananéia; (12) Paranaguá. Ribeira: (13) Sete Barras; (14) Alto Ribeira. Fonte: Zalán \& Oliveira (2005).

que a correção de terreno foi realizada utilizando apenas dados altimétricos restritos ao perfil levantado. Posteriormente, aplicamos a técnica de separação regional-residual por ajuste polinomial aos dados gravimétricos Bouguer. Finalmente, interpretamos a componente gravimétrica residual que foi separada da anomalia observada.

\section{Levantamento e pré-processamento dos dados magnetométricos}

0 levantamento magnetométrico (Fig. 6) envolveu 1.787 estações, distribuídas ao longo de aproximadamente de 45 quilômetros. Realizamos dois perfis, na mesma direção NE-SW, igualmente paralelos à linha de costa, com o objetivo de cruzar perpendicularmente à direção preferencial da região central do Arco de Ponta Grossa. As medidas do campo magnético total foram adquiridas com dois magnetômetros: um ao longo dos perfis (modelo ENVI MAG, fabricação Scintrex, precisão nominal de $0.1 \mathrm{nT}$ ) e outro (modelo UNIMAG II - EG\&G, fabricação Geometrics, precisão nominal de $1 \mathrm{nT}$ ), em duas bases fixas, para monitorar a variação diurna do campo geomagnético. Em ambos os instrumentos registramos três leituras por estação e consideramos a média destas leituras como o valor observado na estação. Para o registro nas bases, realizamos leituras com intervalos de cinco minutos.

0 primeiro perfil inicia na foz do rio Saí-guaçú, na localidade de Barra do Saí, e finaliza no Morro do Cristo, em Guaratuba, totalizando $9.825 \mathrm{~m}$ com 391 estações. A base deste perfil foi estabelecida no Balneário de Coroados (Fig. 6). 0 segundo perfil inicia nas proximidades do morro do Boi, em Caiobá, e finaliza 

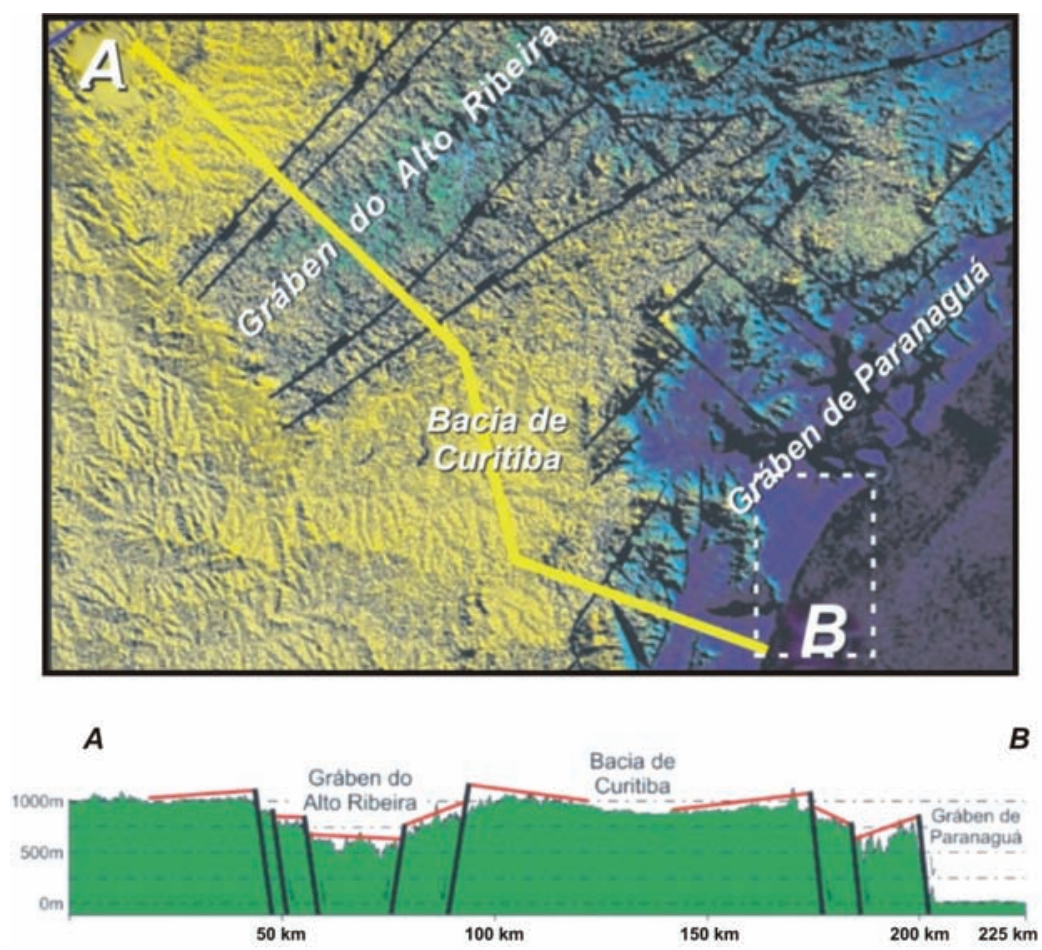

Figura 3 - Mapa e perfil morfoestrutural interpretado dos grábens do Alto Ribeira e Paranaguá e da Bacia de Curitiba (AB). Por uma questão de simplificação, nem todas as falhas do mapa foram indicadas no perfil. Linha vermelha no perfil representa uma interpretação da altitude atual da Superfície de Aplainamento Japi (SAJ). Área de estudo destacada com linha tracejada (modificado de Zalán \& Oliveira, 2005).

no Balneário de Pontal do Sul, totalizando 35.200m com 1.396 estações, cuja base foi implantada no Balneário de Praia de Leste (Fig. 6).

0 pré-processamento dos dados magnetométricos consistiu na correção da variação diurna do campo geomagnético e na remoção posterior de um nível de base médio, de 22.900 nT, considerado representativo do campo principal da Terra na época do levantamento.

\section{Modelagem}

0 processo de modelagem dos dados gravimétricos e magnetométricos foi realizado com base em Talwani et al. (1959) e Talwani \& Heirtzler (1964). Os dados da profundidade do embasamento de três poços situados ao longo do perfil gravimétrico, obtidos da compilação realizada por Lessa et al. (2000), foram introduzidos na interpretação. Os valores de densidade do modelo foram os seguintes: (i) sedimentos indiferenciados, densidade média de $2,0 \mathrm{~g} / \mathrm{cm}^{3}$, variando entre 1,8 e 2,2 $\mathrm{g} / \mathrm{cm}^{3}$; (ii) embasamento indiferenciado, densidade média de $2,8 \mathrm{~g} / \mathrm{cm}^{3}$, oscilando de 2,59 a $3,00 \mathrm{~g} / \mathrm{cm}^{3}$ e (iii) diques básicos, densidade média de $2,91 \mathrm{~g} / \mathrm{cm}^{3}$, variando de 2,5 a 3,2 $\mathrm{g} / \mathrm{cm}^{3}$. As densidades foram obtidas da bibliografia disponível (Telford et al., 1990) uma vez que não foram realizadas medidas nos materiais considerados. Os parâmetros do campo magnético da Terra correspondem aos valores da porção central da área na época do levantamento, ou seja: declinação $=-19^{\circ}$, inclinação $=-35^{\circ}$ e intensidade do campo magnético total $=22.895 \mathrm{nT}$. Dados paleomagnéticos obtidos de Raposo (1992), foram primeiramente aplicados na modelagem de diques de diabásio do Arco de Ponta Grossa por Portela Filho (2003), Portela Filho \& Ferreira (2003) e Portela Filho et al. (2005). Estes dados paleomagnéticos, também empregados neste trabalho, são sintetizados na Tabela 1. A susceptibilidade média utilizada foi de 0,0276 SI, variando de 0,0125 a 0,125 Sl. Como não se observou influência significativa do mergulho dos diques nas anomalias resultantes, por simplicidade os mesmos foram considerados verticais.

Tabela 1 - Estatística básica dos dados paleomagnéticos utilizados na pesquisa.

\begin{tabular}{|c|c|c|}
\hline & Declinação $\left({ }^{\circ}\right)$ & Inclinação $\left(^{\circ}\right)$ \\
\hline Média & 239.14 & -16.72 \\
\hline Desvio & 132.61 & 40.71 \\
\hline Mínimo & 0.30 & -58.00 \\
\hline Máximo & 359 & 58.70 \\
\hline Número & 78 & 78 \\
\hline
\end{tabular}

Modificado de Portela Filho (2003). 


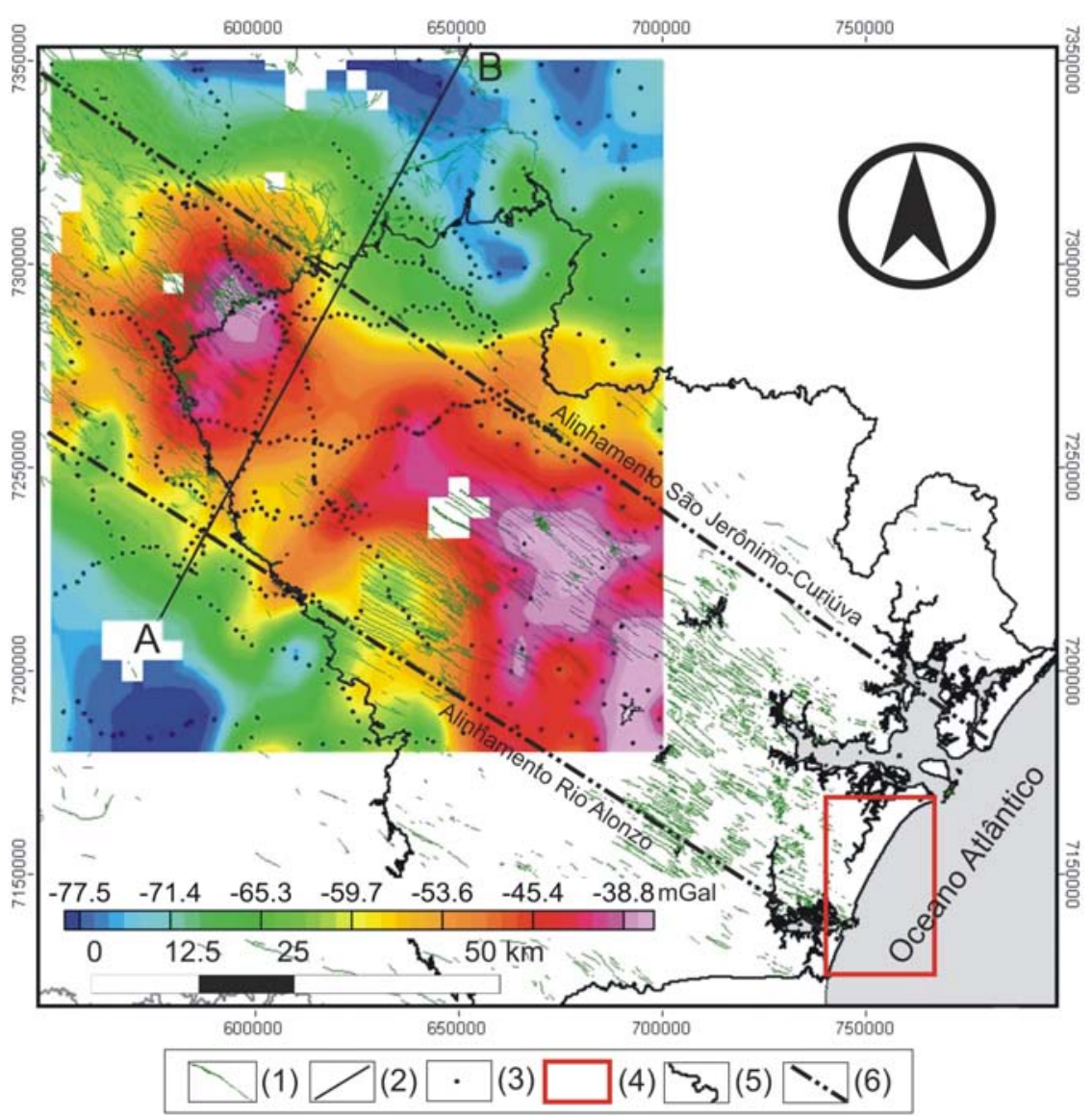

Figura 4 - Mapa da região central do Arco de Ponta Grossa indicando a área de estudo e o alto gravimétrico entre os alinhamentos São Jerônimo-Curiúva e do Rio Alonzo. (1) diques; (2) perfil gravimétrico AB; (3) estações gravimétricas (IAG-USP); (4) área de estudo; (5) escudo paranaense; (6) alinhamentos estruturais-magnéticos (modificado de Ferreira, 1982 a,b e Mineropar, 2001).

\section{RESULTADOS}

\section{Gravimetria}

A Figura 4 mostra o comportamento regional das anomalias gravimétricas. Qualitativamente, observamos um alto gravimétrico orientado segundo NW-SE, o qual corresponde ao trend de maior concentração de diques de diabásio, relacionado à região central do Arco de Ponta Grossa.

Ferreira et al. (1989 a,b) interpretaram um alto gravimétrico semelhante, na mesma direção, localizado na região do Alinhamento de Guapiara (limite setentrional do Arco de Ponta Grossa), como um soerguimento do manto da ordem de $5 \mathrm{~km}$, correspondente a um afinamento crustal de 14\%, considerando a interface crosta-manto a uma profundidade de $35 \mathrm{~km}$. Tal modelo contempla uma seção crustal com grande concentração de diques, em correspondência ao alto gravimétrico, cuja densidade $\left(2,87 \mathrm{~g} / \mathrm{cm}^{3}\right)$ é ligeiramente superior à da crosta continental adjacente $\left(2,85 \mathrm{~g} / \mathrm{cm}^{3}\right)$. Com base nesta interpretação, propo- mos 0 modelo da Figura 7, através da modelagem dos dados do perfil AB (Fig. 4). Para a elaboração do modelo mostrado na Figura 7, utilizamos profundidades, densidades e velocidades das ondas $\mathrm{P}$ de camadas crustais e do manto superior, interpretadas por Bassini (1986) e Rosales (2004).

Como podemos notar no modelo da Figura 7, a espessura da crosta continental superior (CCS) foi estimada em $11 \mathrm{~km}$, densidade de $2,84 \mathrm{~g} / \mathrm{cm}^{3}$ e velocidade das ondas $P$ de $5,7 \mathrm{~km} / \mathrm{s}$. A crosta continental inferior (CCl) foi dividida em duas camadas: a superior (CCI-S), situada entre 11 e $24 \mathrm{~km}$ de profundidade (espessura de $13 \mathrm{~km}$, densidade de $2,98 \mathrm{~g} / \mathrm{cm}^{3}$ e velocidade das ondas $P$ de $6,3 \mathrm{~km} / \mathrm{s}$ ) e a inferior (CCl-I) posicionada entre 24 e $39 \mathrm{~km}$ de profundidade (espessura de $15 \mathrm{~km}$, densidade de $3,09 \mathrm{~g} / \mathrm{cm}^{3}$ e velocidade das ondas $P$ entre 6,3 e 7,8 km/s). As densidades da porção crustal com intrusões de diques foram consideradas, respectivamente, $2,85 \mathrm{~g} / \mathrm{cm}^{3}$ (CCS), $2,99 \mathrm{~g} / \mathrm{cm}^{3}$ (CCI-S) e $3,10 \mathrm{~g} / \mathrm{cm}^{3}$ (CCI-I). A interface crosta-manto foi posicionada a $39 \mathrm{~km}$ de profundidade, a densidade e a velocidade das 


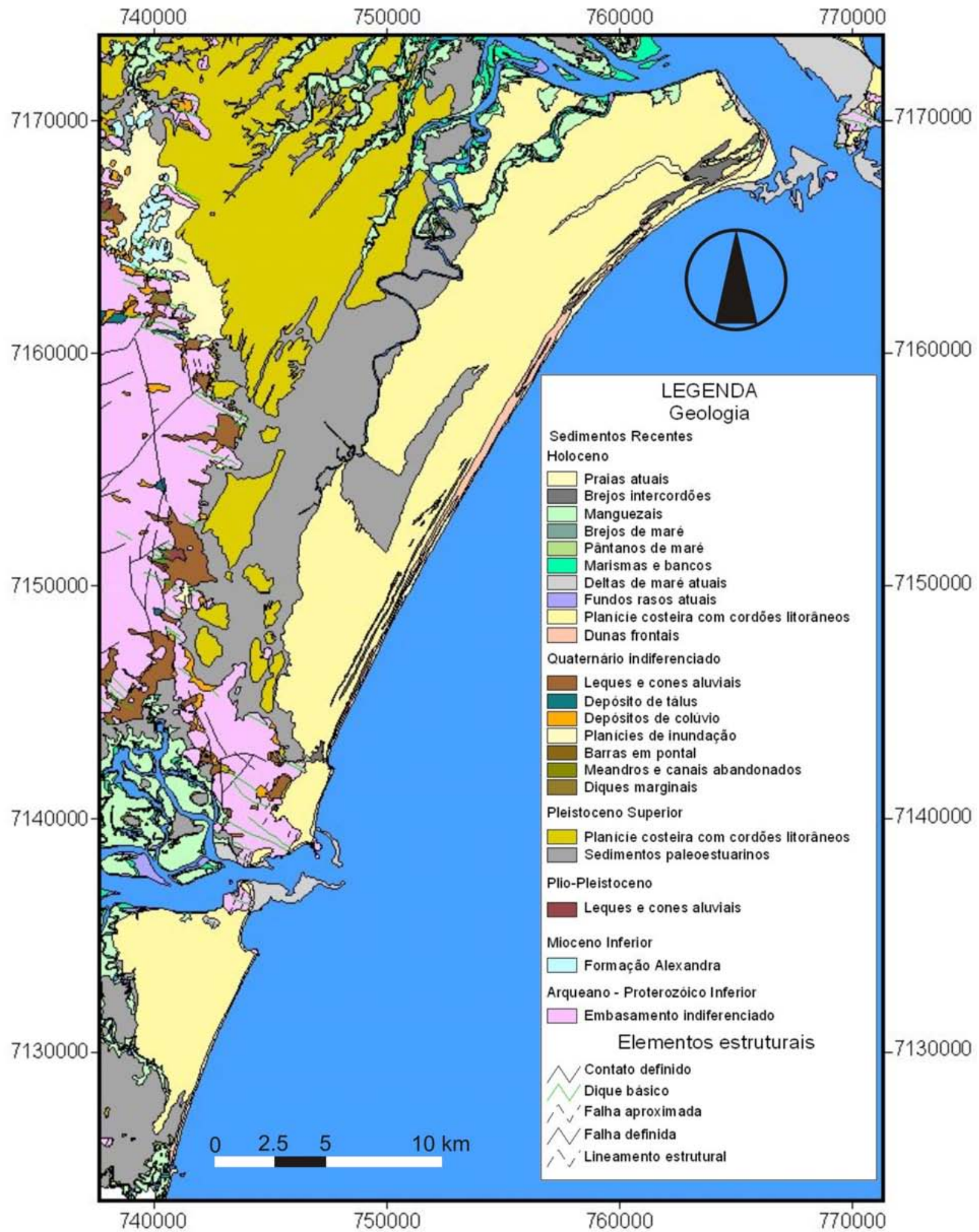

Figura 5 - Mapa geológico da área de estudo (modificado de Angulo, 2004). 


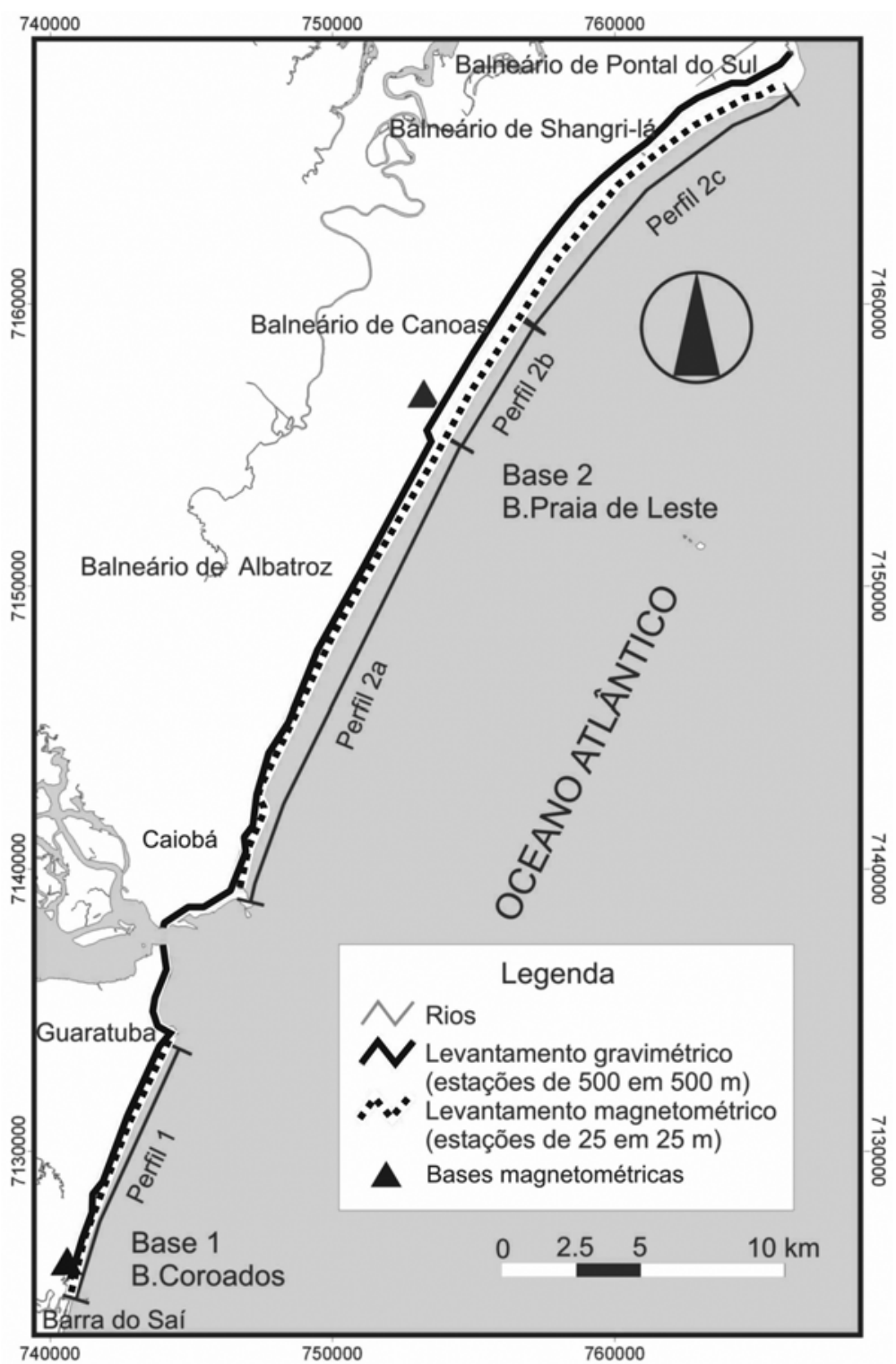

Figura 6 - Localização dos perfis gravimétrico (linha cheia) e magnetométrico (linha tracejada).

ondas $P$ do manto foram estimadas em $3,39 \mathrm{~g} / \mathrm{cm}^{3}$ e $8,1 \mathrm{~km} / \mathrm{s}$, respectivamente. Portanto, 0 alto gravimétrico da Figura 7 pode ser interpretado por um soerguimento do manto da ordem de $4 \mathrm{~km}$, correspondente a um afinameto crustal de cerca de $10 \%$, associado a um segmento da crosta continental com grande concentração de diques, a qual está inserida na região central do Arco de Ponta Grossa (Fig. 4). Conforme ainda a Figura 4, a área de estudo está situada no prolongamento para sudeste do alto gravimétrico.

A partir da análise crítica dos dados das anomalias Bouguer da Figura 8 (veja localização na Fig. 6), verificou-se a neces- sidade da aplicação de um filtro do tipo spline, utilizado para eliminar dados espúrios (picos isolados) e suavizar a curva.

\section{Separação regional-residual}

Realizamos a separação regional-residual com o objetivo de discriminar o sinal gravimétrico produzido por fontes profundas das anomalias gravimétricas de interesse, supostamente geradas por movimentos verticais do embasamento. Para tanto, aplicamos a técnica de separação regional-residual por superfícies polinomiais de $1^{\circ}, 2^{\circ}, 3^{\circ}$ e $4^{\circ}$ graus, as quais foram subtraídas das 

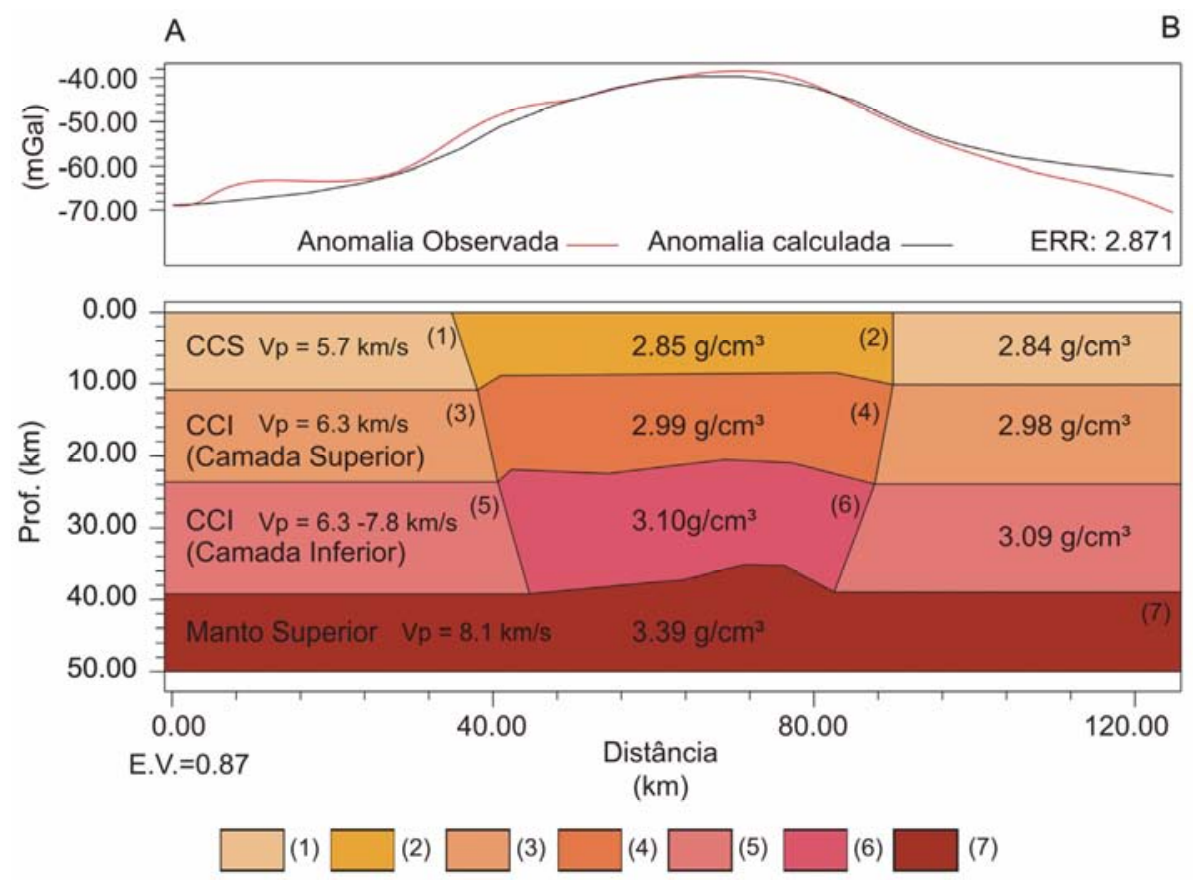

Figura 7 - Modelo gravimétrico do perfil AB (localização na Figura 4) baseado em Bassini (1986), Ferreira et al. (1989 a,b) e Rosales (2004). CCS - crosta continental superior; CCI - crosta continental inferior; (1) CCS sem diques; (2) CCS com diques; (3) CCI camada superior sem diques; (4) CCI camada superior com diques; (5) CCI camada inferior sem diques; (6) CCI camada inferior com diques; (7) manto superior.

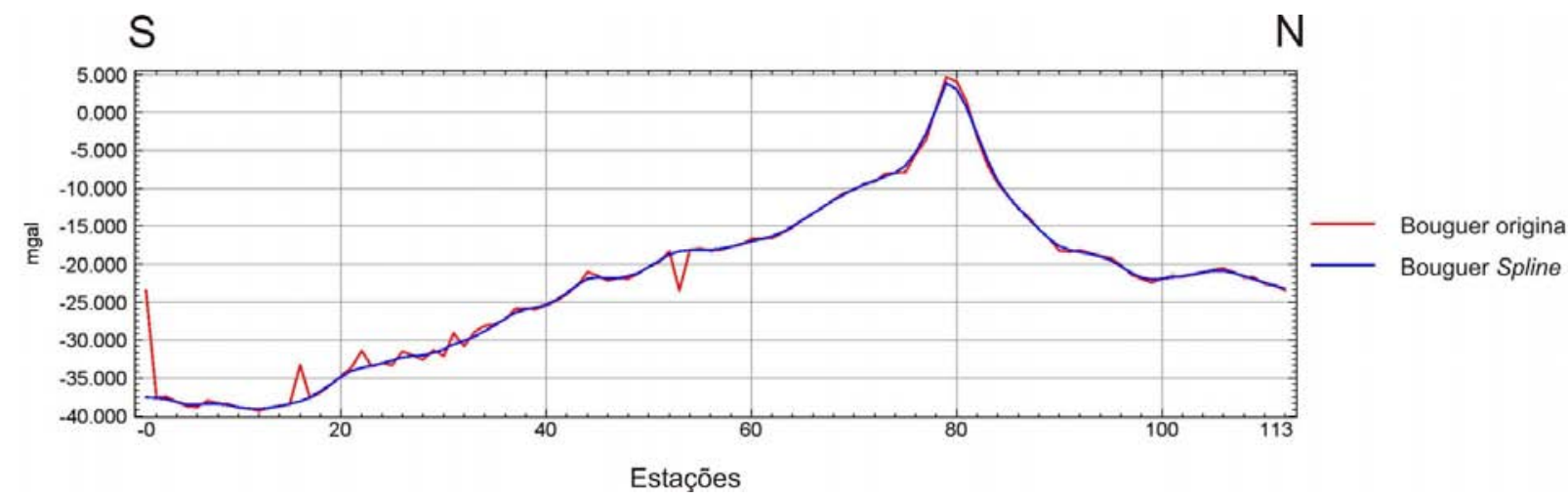

Figura 8 - Anomalia Bouguer com aplicação do filtro spline (localização na Figura 6).

anomalias Bouguer, resultando, respectivamente, nos perfis residuais de $1^{\circ}, 2^{\circ}, 3^{\circ}$ e $4^{\circ}$ graus (Fig. 9).

0 ajuste polinomial é uma das técnicas mais utilizadas para a determinação do campo regional. Polinômios de baixo grau podem não representar o campo medido e parte do campo regional pode ser transferida para o residual. Alternativamente, polinômios de alto grau tendem a se ajustar ao campo medido, incorporando parte do residual. Desta forma a escolha do grau do polinômio que melhor represente o campo regional é subjetiva e depende da experiência do intérprete com a geologia da área de estudo. A Figura 9 (c e d) mostra que as opções de $3^{\circ}$ e $4^{\circ}$ graus são as melhores, uma vez que porções meridionais significativas das respectivas superfícies polinomiais se ajustam adequadamente às anomalias Bouguer, do que decorrem resíduos mais consistentes no restante do perfil. Tendo em vista que 0 embasamento exposto (Fig. 5) foi soerguido através de falhamentos (Mineropar, 2001), entre os municípios de Caiobá e Guaratuba, processo que originou a Baía de Guaratuba, selecionamos o perfil de $4^{\circ}$ grau (Fig. 9d) como o mais representativo do campo gravimétrico residual, pois só aí observamos um alto gravimétrico (AG3, Fig. 9d), em correspondência à realidade geológica.

A partir do perfil gravimétrico residual da Figura 9d notamos 

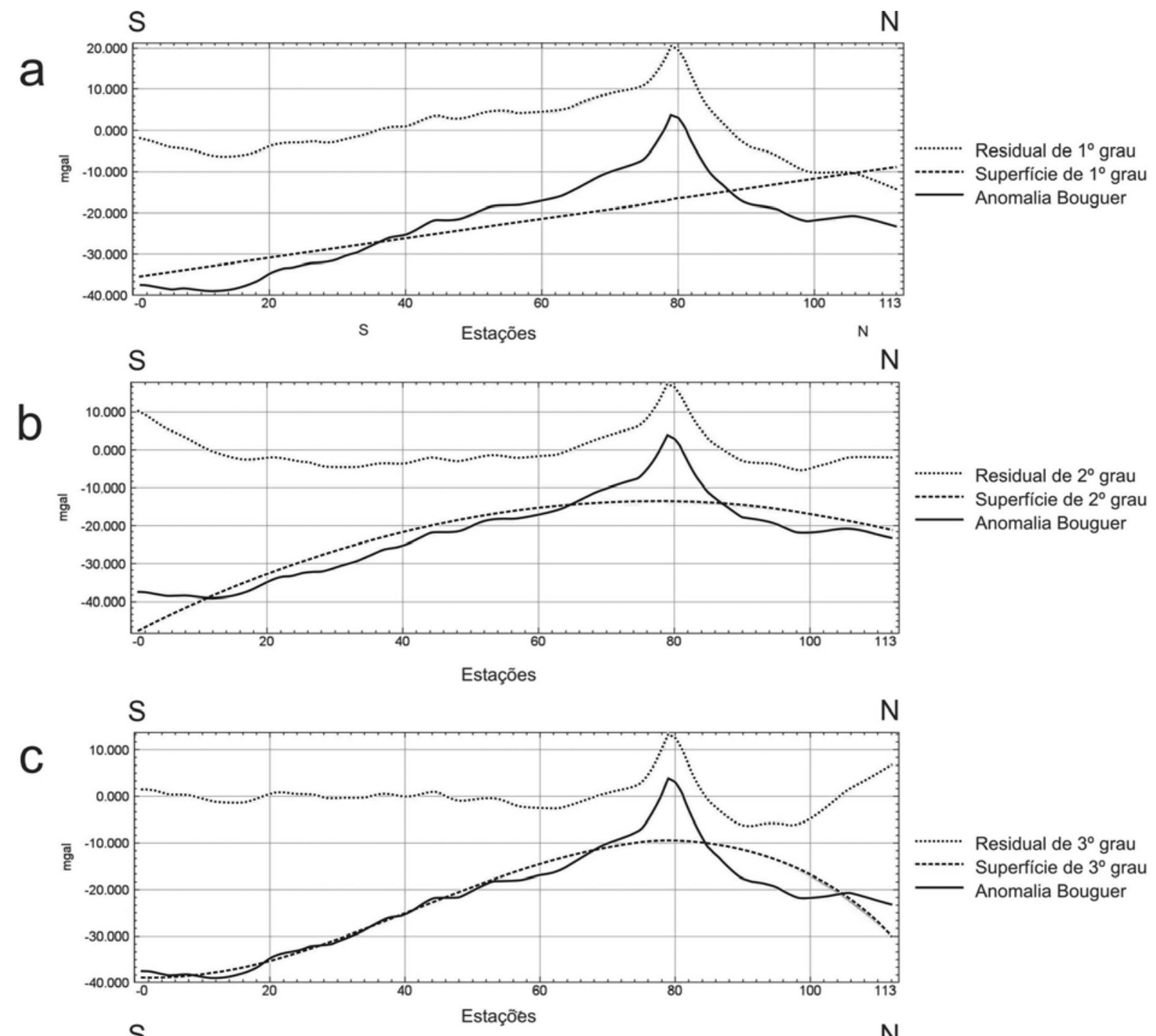

N

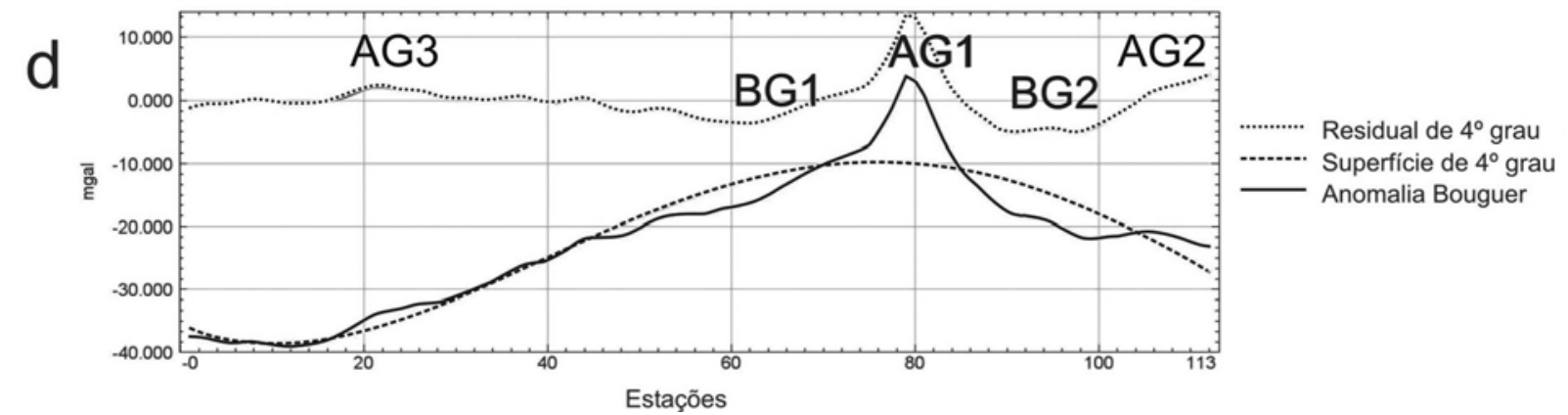

Figura 9 - Perfis das anomalias Bouguer (linha cheia), do regional (linha tracejada) e do residual (linha pontilhada) obtidos a partir de superfícies de tendência do primeiro grau (a), do segundo grau (b), do terceiro grau (c) e do quarto grau (d). AG1 - Alto gravimétrico 1; AG2 - Alto gravimétrico 2; AG3 - Alto gravimétrico 3; BG1 - Baixo gravimétrico 1; BG2 - Baixo gravimétrico 2. 
um alto gravimétrico expressivo (AG1), em sua região centronorte, localizado no Balneário de Canoas, ladeado por dois baixos gravimétricos (BG1 e BG2) situados, respectivamente, nos Balneários de Albatroz e Shangri-lá (Fig. 6). Como o método dos mínimos quadrados é baseado na minimização da soma dos quadrados dos resíduos (Agocs, 1951; Skeels, 1967), gerando anomalias positivas e negativas, esta técnica produzirá pseudo-anomalias com sinais contrários ao da anomalia verdadeira. 0 método por ajuste polinomial robusto, desenvolvido por Beltrão et al. (1991), permite 0 emprego de polinômios de graus elevados e minimiza às pseudo-anomalias características do método dos mínimos quadrados. 0 ajuste polinomial robusto evita tais efeitos através da determinação dos coeficientes por um procedimento iterativo, usando uma seqüência de soluções por mínimos quadrados ponderados, no qual são atribuídos pesos cada vez menores à anomalia residual, até que a influência no campo regional ajustado seja efetivamente eliminada. Entretanto, a seleção do polinômio mais representativo do campo regional deve ser procedida em correspondência às informações a priori derivadas da geologia da área de estudo. Em síntese, apesar dos baixos gravimétricos BG1 e BG2 apresentarem aspectos de pseudo-anomalias, consideramos verdadeiras estas anomalias residuais, pois devem constituir respostas do abatimento de blocos crustais, derivados de movimentos opostos do embasamento, contexto tectônico aceito por diversos autores para a evolução meso-cenozóica do Arco de Ponta Grossa (e.g. Ferreira, 1982 a,b; Zalán \& Oliveira, 2005; Franco, 2006; Strugale et al., 2007).

Além do alto gravimétrico de Canoas (AG1), outros altos gravimétricos de menor expressão são indicados na Figura 9d: um na porção setentrional da área, em Pontal do Sul (AG2), e outro no extremo meridional, em Guaratuba (AG3).

\section{Magnetometria}

Os perfis magnéticos 1 e 2 (a,b,c), localizados na Figura 6, corrigidos da variação diurna, estão representados nas Figuras $10 \mathrm{e}$ 11, respectivamente, os quais indicam também o IGRF médio e a curva resultante da aplicação de um filtro de suavização que corta as altas freqüências do sinal.

Podemos observar na Figura 11 que o segmento 2b apresenta anomalias com grandes amplitudes, contrastando com as demais anomalias do perfil. Deste modo, optamos por dividi-lo em três porções como indicado nas Figuras 12 a 14.

Nos perfis residuais gravimétrico e magnetométrico, notamos na região do Balneário de Canoas a correspondência entre 0 alto gravimétrico AG1 e a zona de predominância das grandes amplitudes das anomalias magnéticas do perfil $2 b$, da ordem de 10.000 nT. Tal coincidência encerra significado geológico, no sentido de que o soerguimento de bloco do embasamento foi acompanhado por fraturas extensionais nas quais os diques de diabásio foram alojados.

\section{Modelagem gravimétrica}

A modelagem dos dados gravimétricos foi realizada separadamente, com o objetivo posterior de verificar a influência da densidade dos diques no modelo final. Desta forma apresentamos dois modelos para cada perfil: um obtido pela modelagem somente dos dados gravimétricos e outro envolvendo os dados gravimétricos e magnéticos.

0 processamento foi realizado utilizando todos os dados gravimétricos, considerando-se fixas as profundidades do embasamento determinadas pelos poços. Entretanto, para fins de apresentação, o perfil foi segmentado seguindo a divisão empregada nos perfis magnéticos (Fig. 11), no sentido de possibilitar comparações com o modelo gerado pela modelagem simultânea. Foram inseridos pontos de referência (1 a 8, Figs. 15 a 18) para posterior comparação das profundidades obtidas pelos dois tipos de modelo.

As Figuras 15 a 18 indicam os modelos geológicos (painéis inferiores) e suas respectivas anomalias gravimétricas (painéis superiores). As anomalias gravimétricas observadas e ajustadas a partir do modelo geológico estão em linhas cheias e tracejadas, respectivamente.

\section{Modelagem gravimétrica-magnética}

Os modelos gerados pela modelagem conjunta dos dados gravimétricos e magnéticos, assim como as anomalias observadas e calculadas, são apresentados nas Figuras 19 a 22.

0 método de modelagem 2D empregado, baseado em Talwani et al. (1959) e Talwani \& Heirtzler (1964), culminou quando 0 ajuste das anomalias observadas e calculadas foi considerado satisfatório, balizado pelo RMS e pela geologia local. Os pontos de referência indicam a mesma posição geográfica nos dois tipos de modelo. Estes dados mostram profundidades distintas ao topo do embasamento, para os modelos gravimétrico e gravimétricomagnético (Tab. 2).

A partir dos dados da Tabela 2 verificamos que as profundidades ao topo do embasamento são maiores no modelo gravimétrico, em comparação ao modelo gravimétrico-magnético. Isto mostra a influência da densidade dos diques na modelagem dos dados. Esta variação de profundidade nos mesmos pontos é atribuída à diferença de densidade entre 0 embasamento e os diques básicos. Assim, é possível constatar que em segmentos crustais contaminados por intrusões básicas, como no contexto do Arco de Ponta Grossa, a modelagem conjunta de dados gravimétricos e magnetométricos, certamente, é mais adequada. 


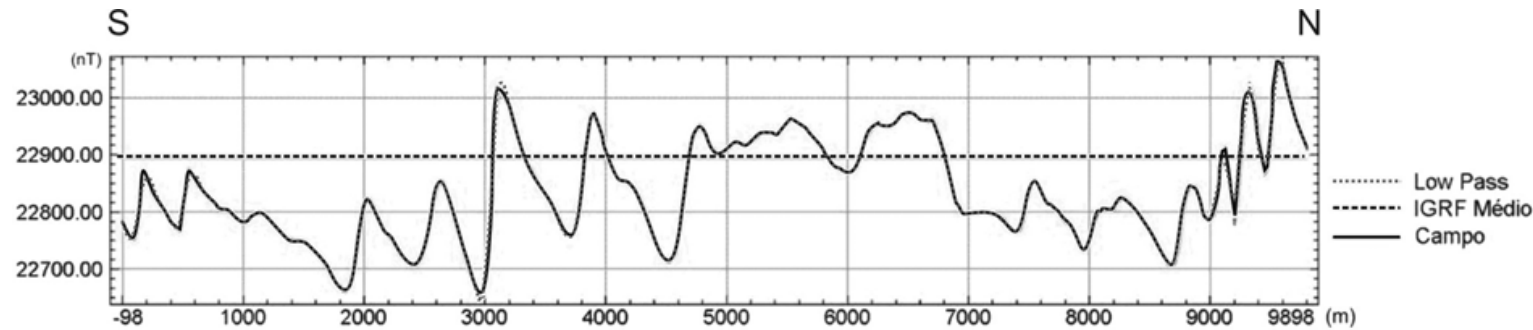

Figura 10 - Perfil magnetométrico 1 (localização na Figura 6; Low Pass - linha pontilhada; IGRF Médio - linha tracejada; Campo - linha cheia).

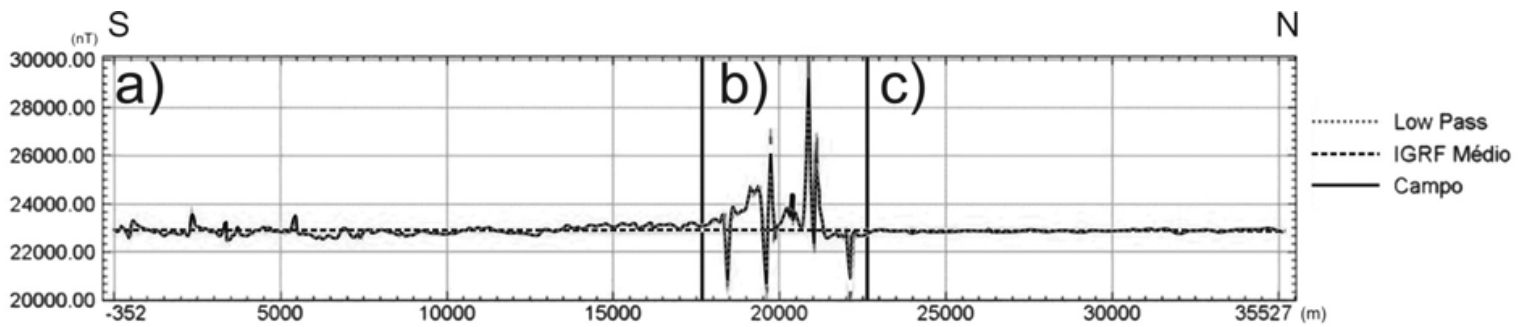

Figura 11 - Perfil magnetométrico 2 indicando os segmentos 2a, 2b e 2c (vide localização na Figura 6; Low Pass - linha pontilhada; IGRF Médio - linha tracejada; Campo - linha cheia).

Tabela 2 - Pontos de referência com profundidades ao topo do embasamento calculadas para os modelos gravimétrico $e$ gravimétrico-magnético

\begin{tabular}{|c|c|c|c|}
\hline Perfil & Ponto & $\begin{array}{c}\text { Mod. } \\
\text { Gravimétrico } \\
\text { Prof. (m) }\end{array}$ & $\begin{array}{c}\text { Mod. } \\
\text { Grav./Mag. } \\
\text { Prof. (m) }\end{array}$ \\
\hline 1 & 1 & 121 & 50 \\
\hline 1 & 2 & 28 & 14 \\
\hline $2 \mathrm{a}$ & 3 & 168 & 72 \\
\hline $2 \mathrm{a}$ & 4 & 191 & 116 \\
\hline $2 \mathrm{~b}$ & 5 & 126 & 45 \\
\hline $2 \mathrm{~b}$ & 6 & 11 & 13 \\
\hline $2 \mathrm{c}$ & 7 & 365 & 130 \\
\hline $2 \mathrm{c}$ & 8 & 275 & 50 \\
\hline
\end{tabular}

Na Figura 23 podemos visualizar o modelo geológico do Gráben de Paranaguá na área de estudo, o qual também é exibido em perspectiva associado ao modelo digital de elevação (MDE, Fig. 24).

\section{Estimativa da extensão crustal}

A primeira estimativa de extensão crustal do Arco de Ponta Grossa (APG), a partir da modelagem aeromagnética de diques de diabásio, foi realizada por Ferreira et al. (1989 a,b). Nestes trabalhos, os autores determinaram uma extensão mínima de $18 \%$, associada a um afinamento da crosta de $14 \%$, na região do Alinhamento de Guapiara (limite setentrional do APG), uma vez que 0 fraturamento rúptil teria sido precedido em certo grau por extensão dúctil, esta não estimada. De acordo com Riccomini (1995), tais valores de extensão e afinamento crustais seriam da mesma ordem de grandeza e indicativos de um regime de cisaIhamento praticamente puro.

Tendo como base as espessuras dos diques de diabásio calculadas neste trabalho, foi possível estimar a extensão crustal mínima nas áreas levantadas pelos perfis magnéticos. 0 procedimento para esta estimativa, proposto por Ferreira et al. (1989 a,b), também utilizado por Portela Filho (2003), Portela FiIho \& Ferreira (2003) e Portela Filho et al. (2005), foi baseado na equação (1):

$$
E=\frac{\varepsilon_{m}}{L \cos \theta} \times 100
$$

onde $E$ é 0 estiramento crustal mínimo, $\varepsilon_{m}$ é a somatória das espessuras dos diques, $L$ é 0 comprimento do perfil e $\theta$ é 0 ângulo entre a direção perpendicular aos diques e a orientação do perfil, que no caso foi de sete graus. Os resultados destes parâmetros (Tab. 3) indicaram uma taxa de extensão média de $27 \%$, relativamente aos $45 \mathrm{~km}$ de perfis magnéticos, e uma freqüência pouco superior a quatro diques/km.

Tabela 3 - Estimativas de extensão crustal na área de estudo.

\begin{tabular}{|c|c|c|c|c|c|}
\hline Perfil & $\begin{array}{c}\mathrm{N}^{\circ} \text { de } \\
\text { diques }\end{array}$ & $\begin{array}{c}\text { Frequêêcia } \\
\text { (diques/km) }\end{array}$ & $\mathrm{e}(\mathrm{m})$ & $\mathrm{L}(\mathrm{m})$ & $\mathrm{E}(\%)$ \\
\hline 1 & 23 & 1.8 & 2729 & 12768.3 & 23.9 \\
\hline $2 \mathrm{a}$ & 56 & 2.7 & 6103 & 20541.5 & 29.9 \\
\hline $2 \mathrm{~b}$ & 92 & 18.8 & 2126 & 4877.1 & 43.9 \\
\hline 2c & 47 & 3.3 & 3152 & 14301.9 & 22.20 \\
\hline Total & 218 & 4.15 & 14110 & 52488.8 & 27.08 \\
\hline
\end{tabular}


$\mathrm{S}$

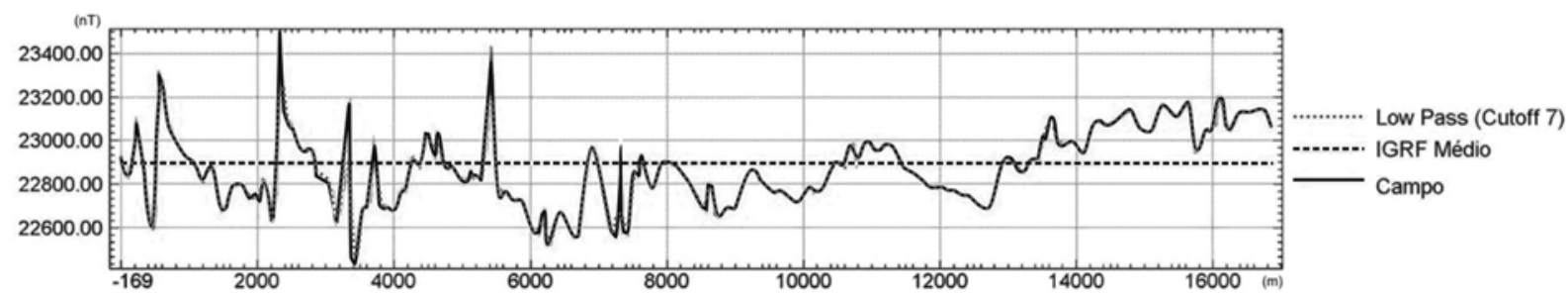

Figura 12 - Perfil magnetométrico 2a (localização na Figura 6; Low Pass - linha pontilhada; IGRF Médio - linha tracejada; Campo - linha cheia).

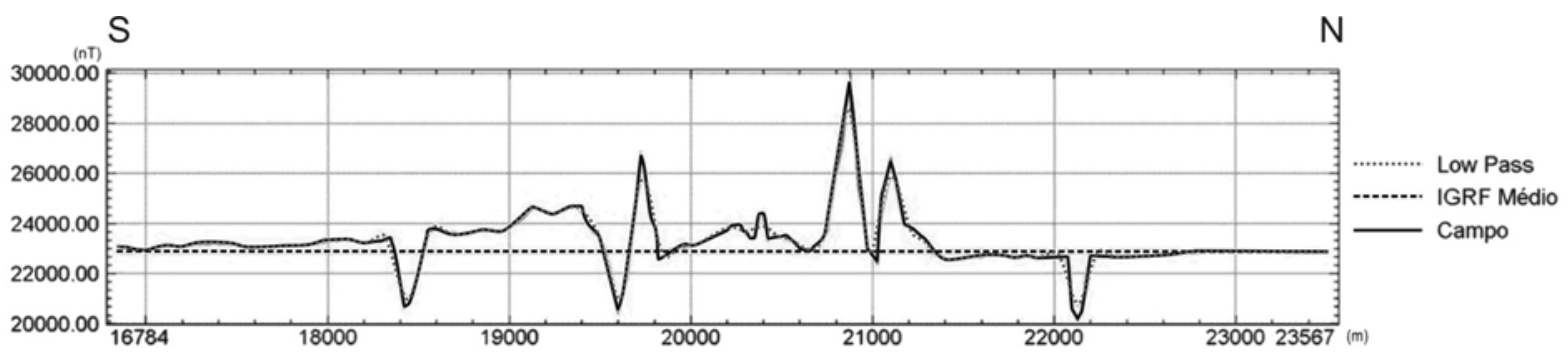

Figura 13 - Perfil magnetométrico 2b (localização na Figura 6; Low PasS - linha pontilhada; IGRF Médio - linha tracejada; Campo - linha cheia).

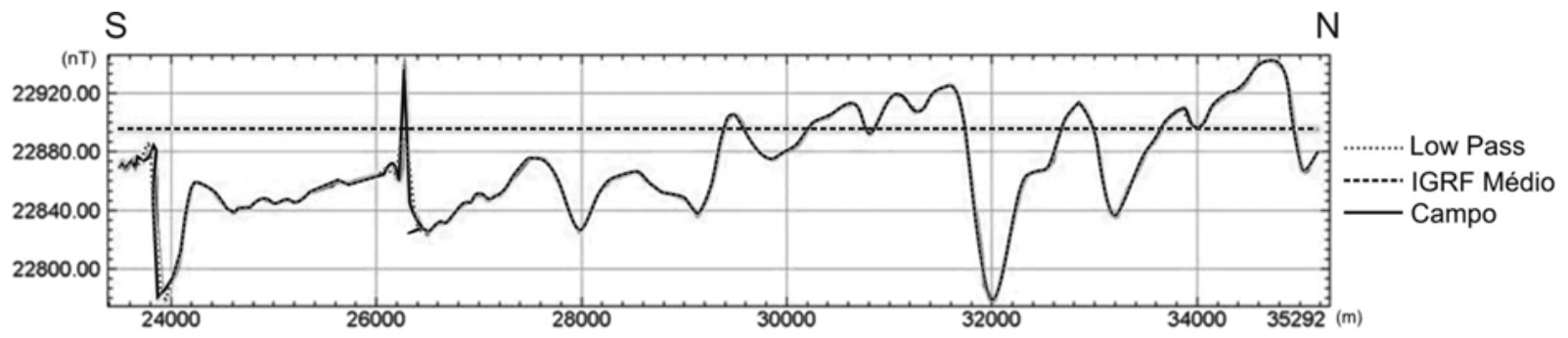

Figura 14 - Perfil magnetométrico 2c (localização na Figura 6; Low Pass - linha pontilhada; IGRF Médio - linha tracejada; Campo - linha cheia).

\section{DISCUSSÃO E CONCLUSÕES}

Franco (2006), avaliando a evolução do Arco de Ponta Grossa (APG), entre os alinhamentos de Guapiara e São JerônimoCuriúva, durante o Meso-Cenozóico, com base em termocronologia por traços de fissão em apatitas, identificou cinco eventos térmicos $(A, B, C, D$ e E) responsáveis pela estruturação do APG a partir do Cretáceo. 0 evento $A$ correspondeu a um aquecimento generalizado em torno de $130 \mathrm{Ma}$, vinculado à ruptura do Gondwana Sul-Ocidental e conseqüente geração do Oceano Atlântico-Sul, cujo rifteamento se deu entre 134 e $111 \mathrm{Ma}$, de acordo com Zalán \& Oliveira (2005). 0 evento B, caracterizado por um resfriamento em $110 \mathrm{Ma}$, se relacionou ao início de um levantamento epirogenético da crosta continental, entre $109 \mathrm{e}$ $89 \mathrm{Ma}$ (Zalán \& Oliveira 2005), síncrono à reativação de antigas zonas de cisalhamento ainda coligadas ao evento de ruptura continental (Franco, 2006). 0 evento C, identificado por um aquecimento em $90 \mathrm{Ma}$, foi subordinado a uma ascensão regional in- terpretada por Franco (2006) como reflexo do soerguimento do Arco de Ponta Grossa. Este soerguimento pode corresponder ao alto gravimétrico regional da Figura 4 e ao modelo geológico da Figura 7 dele decorrente. Para Zalán \& Oliveira (2005), a ascensão entre 89 e 65 Ma foi desprovida de tectonismo e responsável pelo que denominaram Serra do Mar Cretácea (SMC) e pela conseqüente implantação de um megaplanalto de cerca de $300.000 \mathrm{~km}^{2}$ na região sudeste do Brasil. 0 final do soerguimento, no limite Cretáceo-Terciário (65 Ma), materializado pela Superfície de Aplainamento Japi, nivelou o megaplanalto em torno de 2.000 metros em relação ao nível do mar atual, de acordo com Zalán \& Oliveira (2005). Este evento erosivo, denominado D por Franco (2006), foi acompanhado por um resfriamento em $60 \mathrm{Ma}$.

Como decorrência da instabilidade isostática, provocada conjuntamente pela ascensão de um grande volume de rocha e pela subsidência das bacias de Campos e Santos, iniciou-se 0 

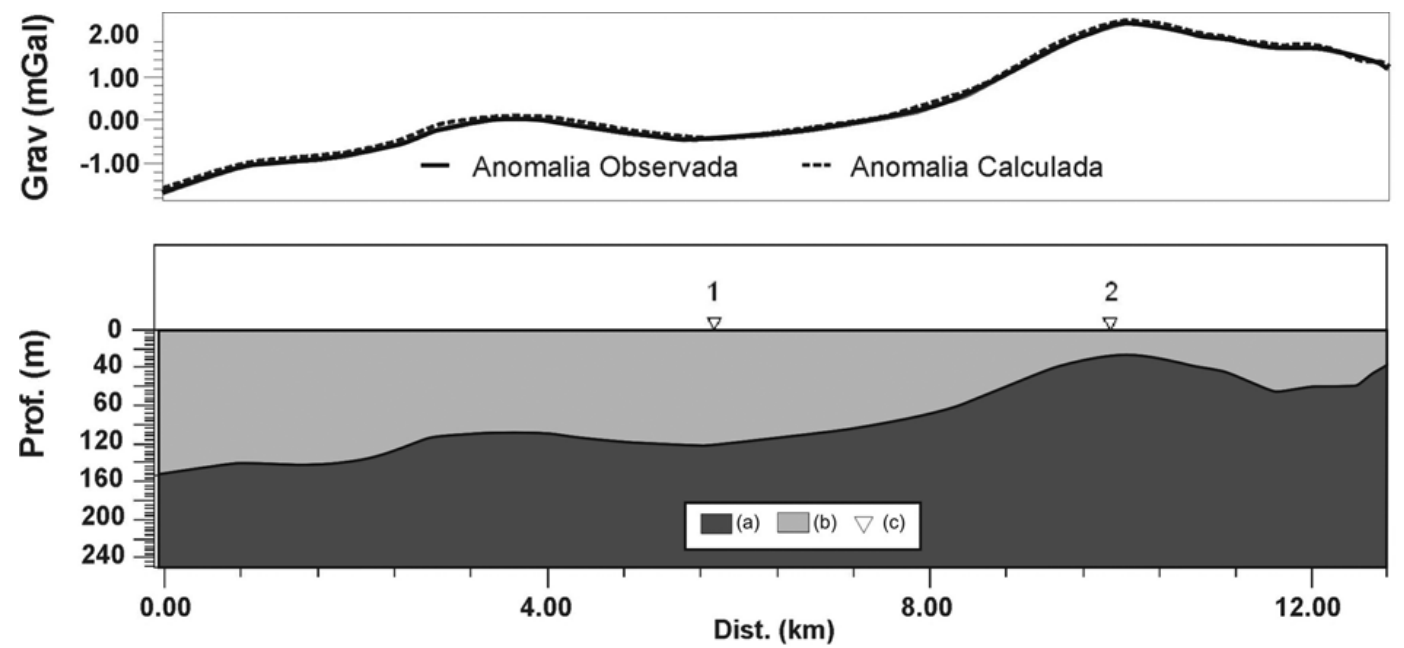

\section{E.V.: $10 \mathrm{x}$}

Figura 15 - Perfil 1: anomalias gravimétricas (observada - linha cheia; calculada - linha tracejada) e o modelo geológico. (a) embasamento indiferenciado $\left(\rho=2,8 \mathrm{~g} / \mathrm{cm}^{3}\right)$; (b) sedimentos indiferenciados $\left(\rho=2,0 \mathrm{~g} / \mathrm{cm}^{3}\right)$; (c) pontos de referência.
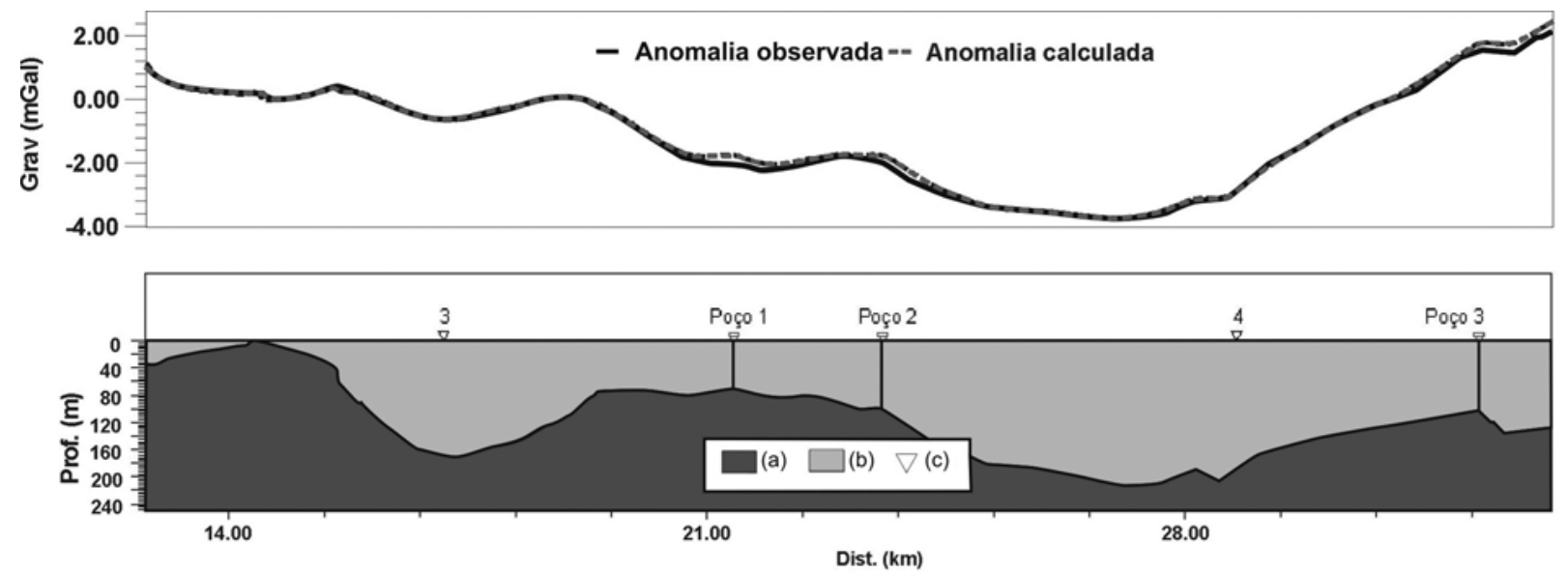

\section{E.V.: $10 \mathrm{x}$}

Figura 16 - Perfil 2a: anomalias gravimétricas (observada - linha cheia; calculada - linha tracejada) e o modelo geológico. (a) embasamento indiferenciado $\left(\rho=2,8 \mathrm{~g} / \mathrm{cm}^{3}\right)$; (b) sedimentos indiferenciados $\left(\rho=2,0 \mathrm{~g} / \mathrm{cm}^{3}\right)$; (c) pontos de referência.

colapso gravitacional em $58 \mathrm{Ma}, 0$ qual perdurou durante boa parte do Cenozóico, até $20 \mathrm{Ma}$, gerando o Sistema de Riftes Cenozóicos do Sudeste do Brasil (Zalán \& Oliveira 2005). 0 clímax deste processo correspondeu ao Mesoeoceno, mais precisamente ao período Lutetiano (48,6-40,4 Ma), intervalo geocronológico identificado em todas as bacias marginais brasileiras sob a forma de uma notável discordância. Este conjunto de fenômenos, denominado por Franco (2006) de evento $E$, foi acompanhado por um resfriamento em 30-20 Ma, em correspondência à atuação de ciclos erosivos e instalação de bacias tafrogênicas. Possivelmente neste tempo se estabeleceu, por colapso gravitacional, 0 Gráben de Paranaguá.

Após a instalação dos grábens formados pelo abatimento da SMC, iniciou-se o processo deposicional. São notados sedimentos basais clásticos do Neo-Eoceno em todas as bacias do SRCSB (Riccomini et al., 2004). 0 abatimento de blocos continuou pelo Neo-Eoceno/Oligoceno/Eomioceno, que corresponde às idades da maioria dos depósitos sedimentares do SRCSB.

Neste contexto, os modelos geológicos das Figuras 23 e 24 representam a continuidade da região central do Arco de Ponta Grossa rumo à plataforma continental e pode refletir movimentos verticais opostos de blocos do embasamento sob os sedimen- 

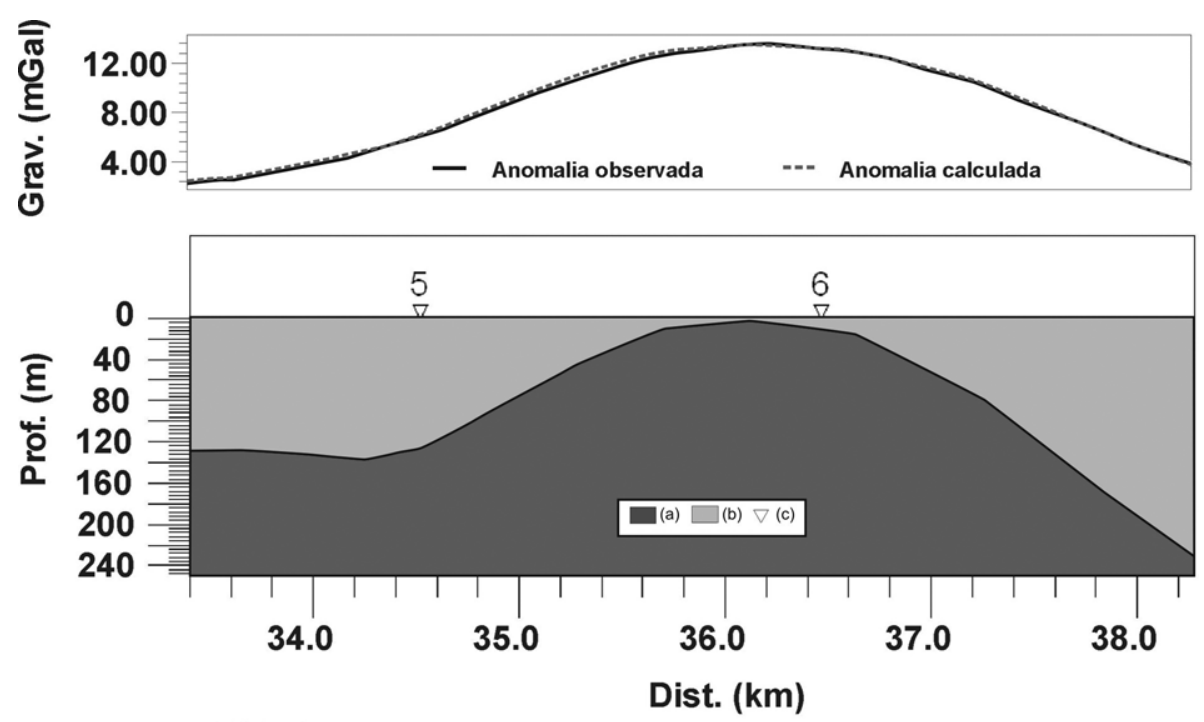

E.V.: $10 x$

Figura 17 - Perfil 2b: anomalias gravimétricas (observada - linha cheia; calculada - linha tracejada) e o modelo geológico. (a) embasamento indiferenciado $\left(\rho=2,8 \mathrm{~g} / \mathrm{cm}^{3}\right)$; (b) sedimentos indiferenciados $\left(\rho=2,0 \mathrm{~g} / \mathrm{cm}^{3}\right)$; (c) pontos de referência.

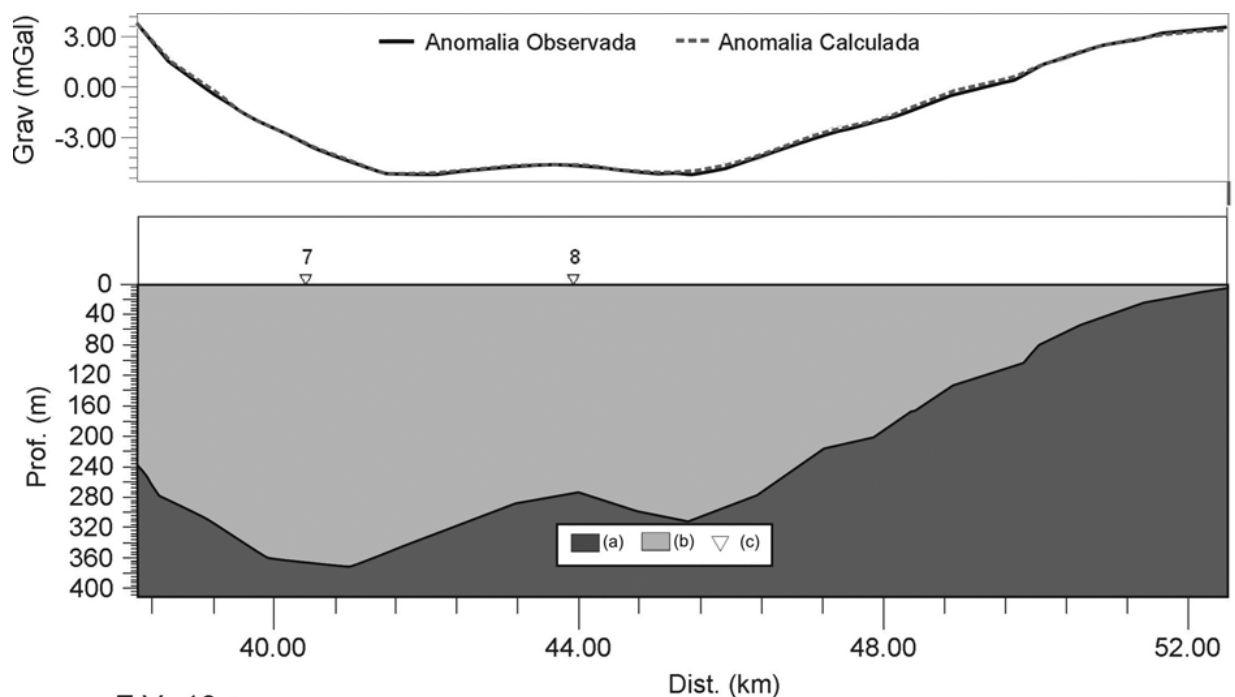

E.V.: $10 \mathrm{x}$

Dist. $(\mathrm{km})$

Figura 18 - Perfil 2c: anomalias gravimétricas (observada - linha cheia; calculada - linha tracejada) e o modelo geológico. (a) embasamento indiferenciado $\left(\rho=2,8 \mathrm{~g} / \mathrm{cm}^{3}\right)$; (b) sedimentos indiferenciados $\left(\rho=2,0 \mathrm{~g} / \mathrm{cm}^{3}\right)$; (c) pontos de referência.

tos da planície costeira paranaense, responsáveis pelas principais feições propostas como o Alto Estrutural de Canoas e os baixos estruturais de Albatroz e Shangri-lá (AG1, BG1 e BG2, respectivamente), além dos altos de Pontal do Sul e Guaratuba (AG2 e AG3, respectivamente). De forma semelhante à interpretação de Souza (1995) e Souza et al. (1996), para o substrato da planície costeira Cananéia-Iguape, sul do Estado de São Paulo, o Alto Estrutural de Canoas, que encerra anomalias magnéticas da ordem de $10.000 \mathrm{nT}$ (Fig. 21), é possivelmente limitado por zonas de falhas normais, de direção NW-SE, também preenchidas por diques de diabásio, relacionadas às reativações cenozóicas de estruturas do Arco de Ponta Grossa. Estas zonas de falhas denotam forte gradiente vertical, como podemos observar, por exemplo, na Figura 23, em apenas 3,5 km de distância, 0 desnível de aproximadamente de 87 metros do topo do embasamento, entre 0 poço 3, com 100 metros de profundidade, e a espessura calculada dos sedimentos sobre o Alto Estrutural de Canoas, de 13 metros (Ponto 6, Tab. 2 e Fig. 21). Já os baixos estruturais contíguos 

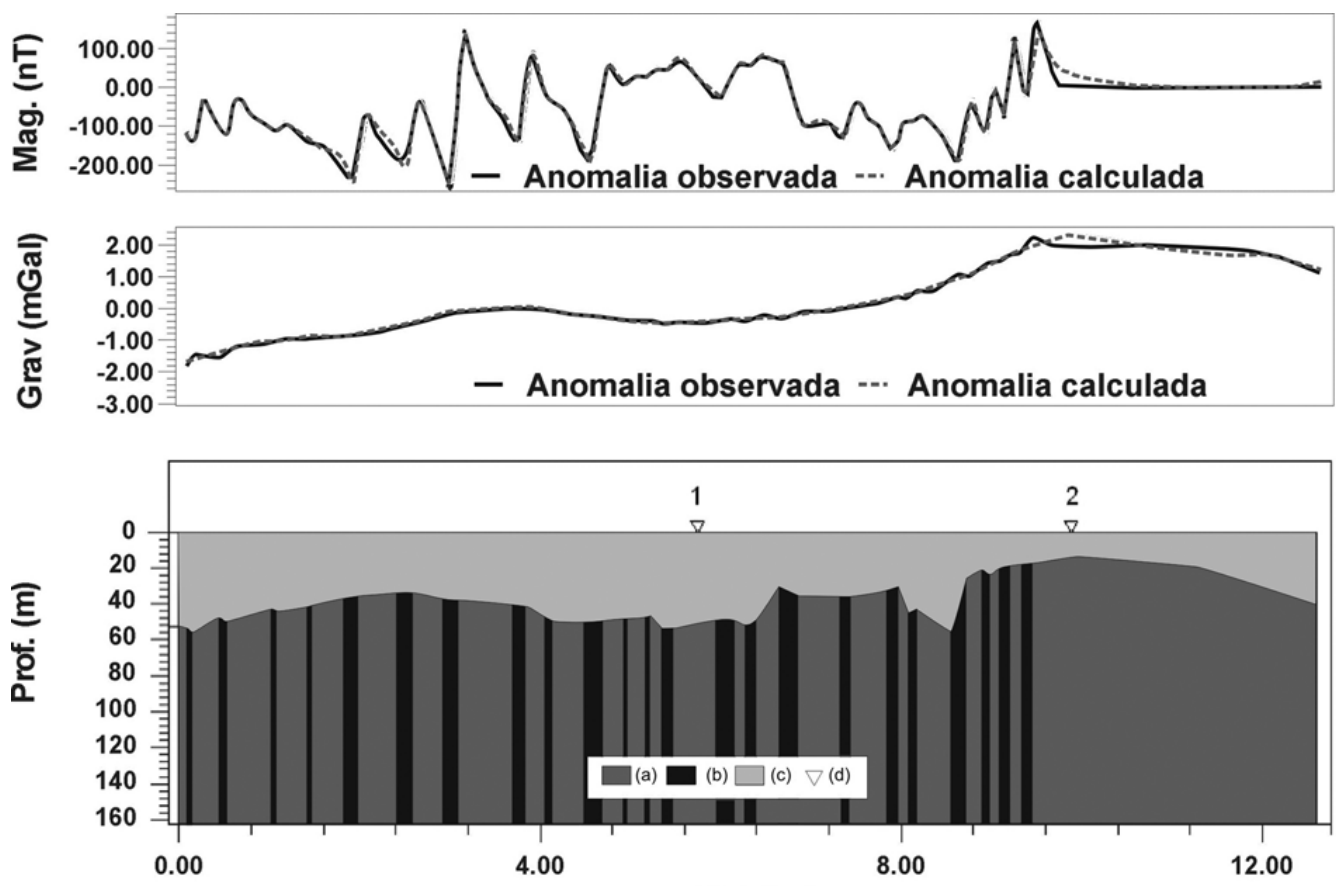

E.V.: $20 x$

Dist. (km)

Figura 19 - Perfil 1: anomalias gravimétricas e magnéticas (observada - linha cheia; calculada - linha tracejada) e 0 modelo geológico. (a) embasamento indiferenciado; (b) diques; (c) sedimentos indiferenciados; (d) pontos de referência. Declinação magnética $=-19^{\circ}$; Inclinação do campo magnético $=-35^{\circ} ;$ Intensidade do campo magnético total $=22.895 \mathrm{nT}$.
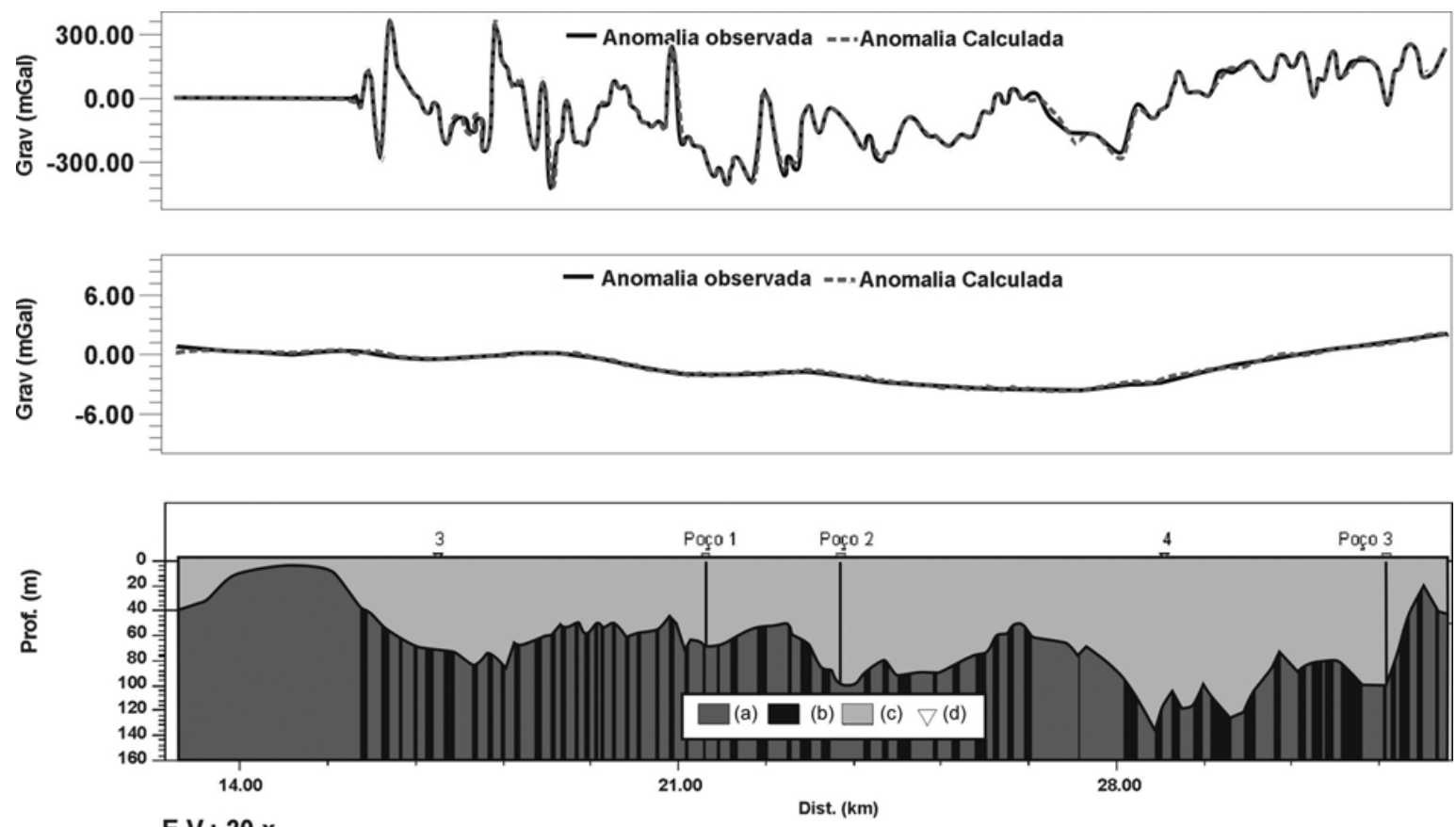

E.V.: $20 \mathrm{x}$

Figura 20 - Perfil 2a: anomalias gravimétricas e magnéticas (observada - linha cheia; calculada - linha tracejada) e o modelo geológico. (a) embasamento indiferenciado; (b) diques; (c) sedimentos indiferenciados; (d) pontos de referência. Declinação magnética $=-19^{\circ}$; Inclinação do campo magnético $=-35^{\circ}$; Intensidade do campo magnético total $=22.895 \mathrm{nT}$. 


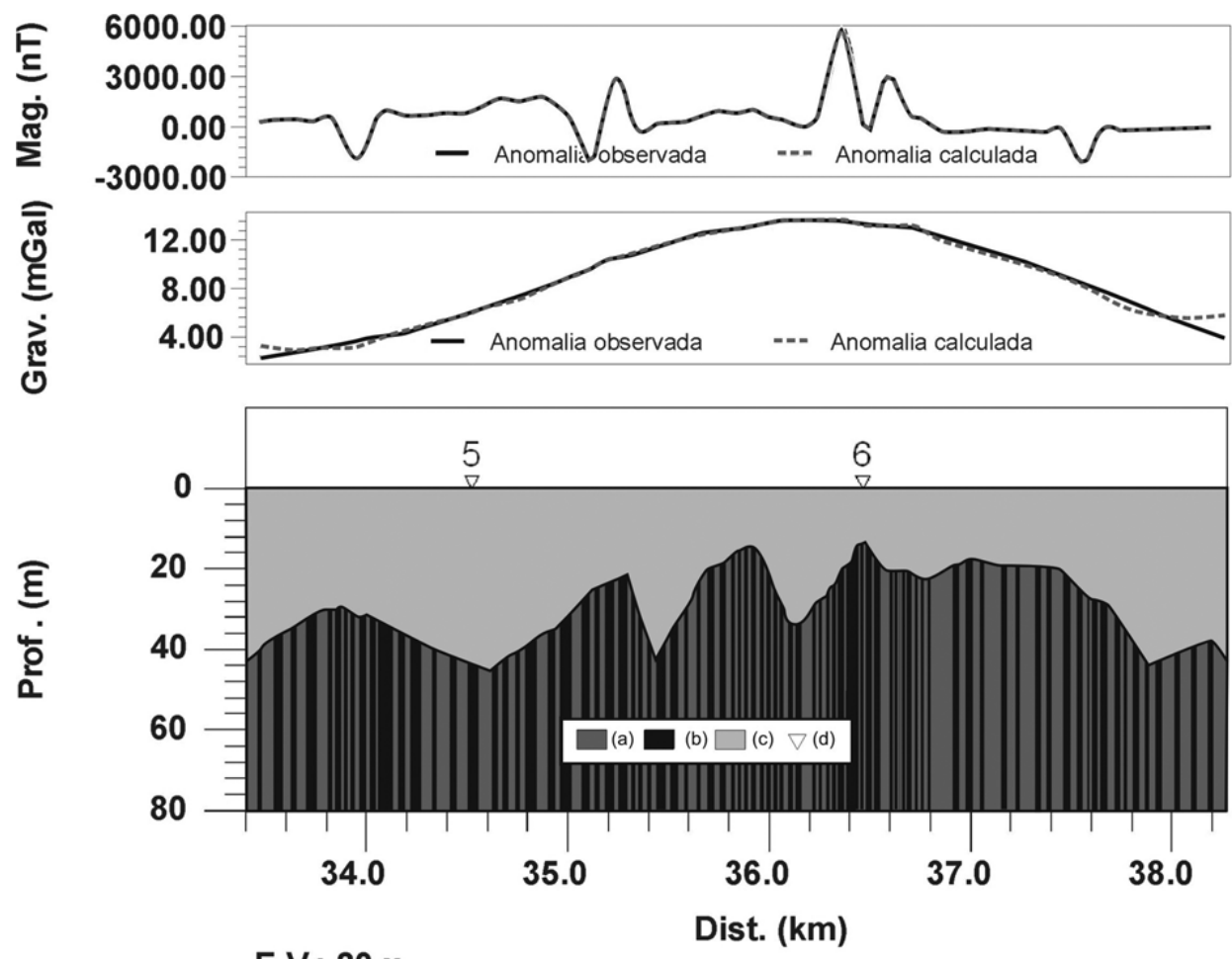

Figura 21 - Perfil 2b: anomalias gravimétricas e magnéticas (observada - linha cheia; calculada - linha tracejada) e o modelo geológico. (a) embasamento indiferenciado; (b) diques; (c) sedimentos indiferenciados; (d) pontos de referência. Declinação magnética $=-19^{\circ}$; Inclinação do campo magnético $=-35^{\circ}$; Intensidade do campo magnético total $=22.895 \mathrm{nT}$.
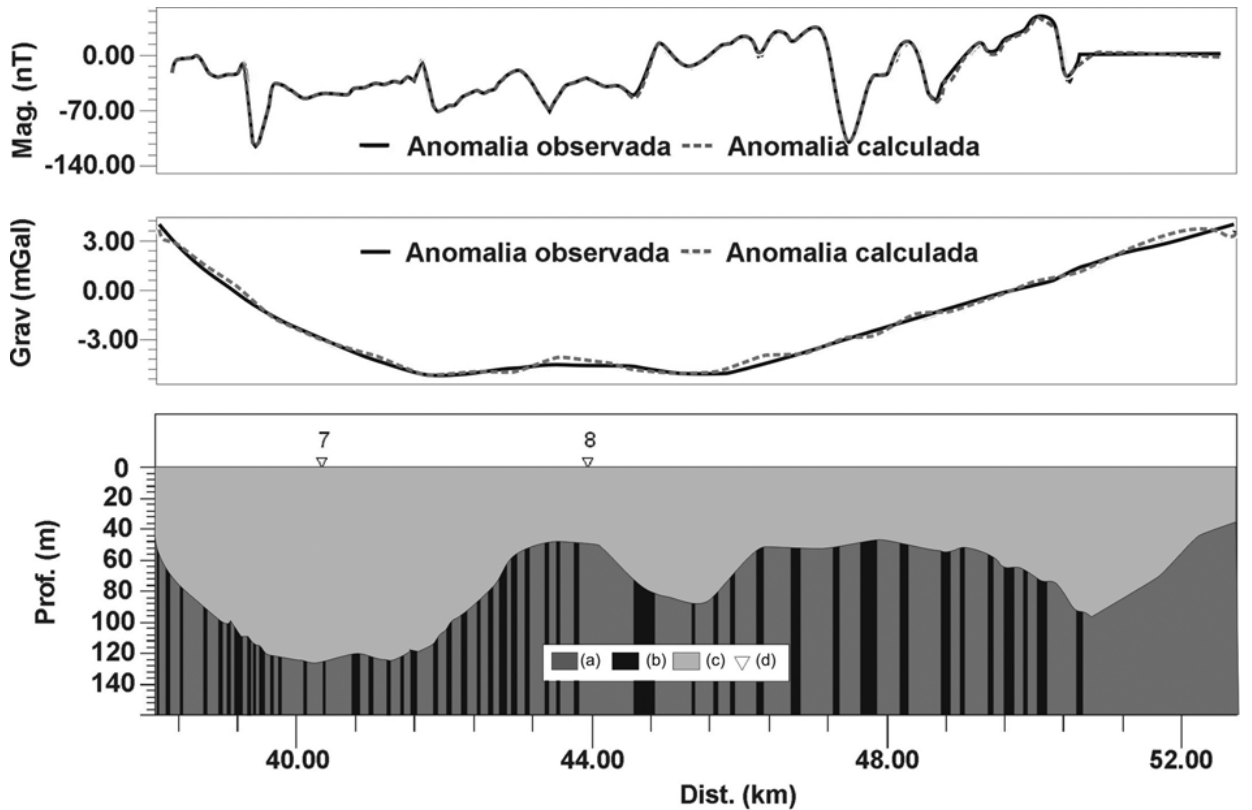

E.V.: $20 \mathrm{x}$

Figura 22 - Perfil 2c: anomalias gravimétricas e magnéticas (observada - linha cheia; calculada - linha tracejada) e o modelo geológico. (a) embasamento indiferenciado; (b) diques; (c) sedimentos indiferenciados; (d) pontos de referência. Declinação magnética $=-19^{\circ}$; Inclinação do campo magnético $=-35^{\circ}$; Intensidade do campo magnético total $=22.895 \mathrm{nT}$. 


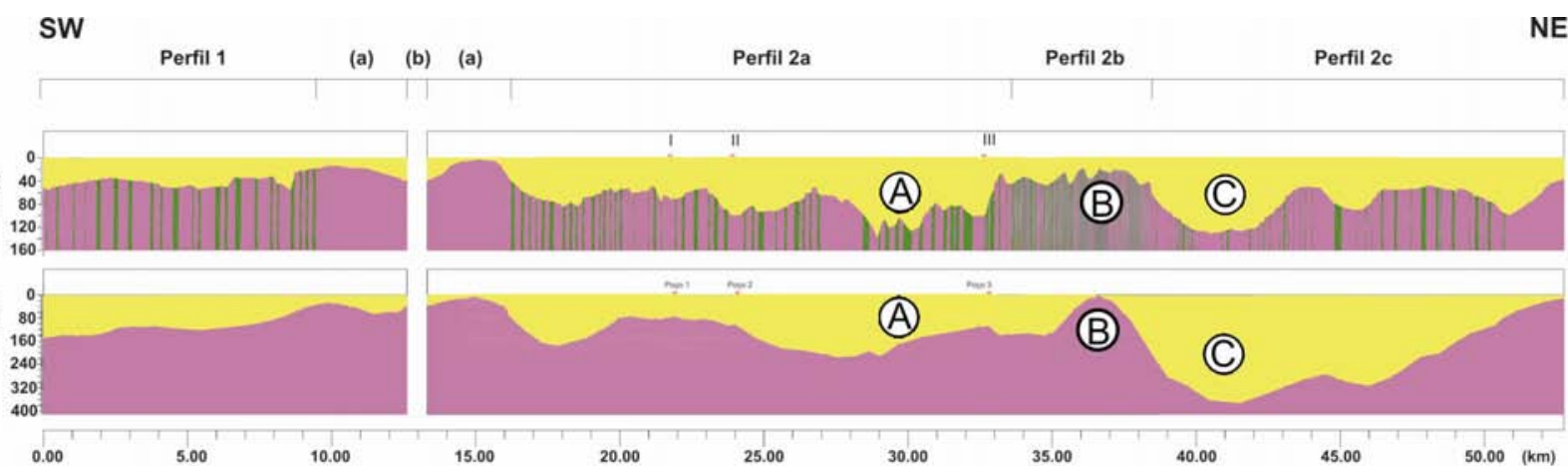

Material geológico

$\square$ Embasamento indiferenciado

Diques

Sedimentos indiferenciados

\section{Dados de Profundidade}

I. Poço 1- $70 \mathrm{~m} \mathrm{(*)}$

II - Poço $2-100 \mathrm{~m}\left({ }^{*}\right.$

III - Poço 3 - $100 \mathrm{~m}(*)$

(a) - Area intensammente urbanizada, sem dados magnetométricos

(b) - Baia de Guaratuba, sem dados

\section{(") - Fonte: Lessa et al. 2000}

Figura 23 - Modelo geológico do Gráben de Paranaguá na área de estudo. (1) embasamento indiferenciado (lilás); (2) diques (verde); (3) sedimentos indiferenciados (amarelo); (A) Baixo Estrutural de Albatroz; (B) Alto Estrutural de Canoas; (C) Baixo Estrutural de Shangri-lá; I (Poço 1); II (Poço II); III (Poço III).

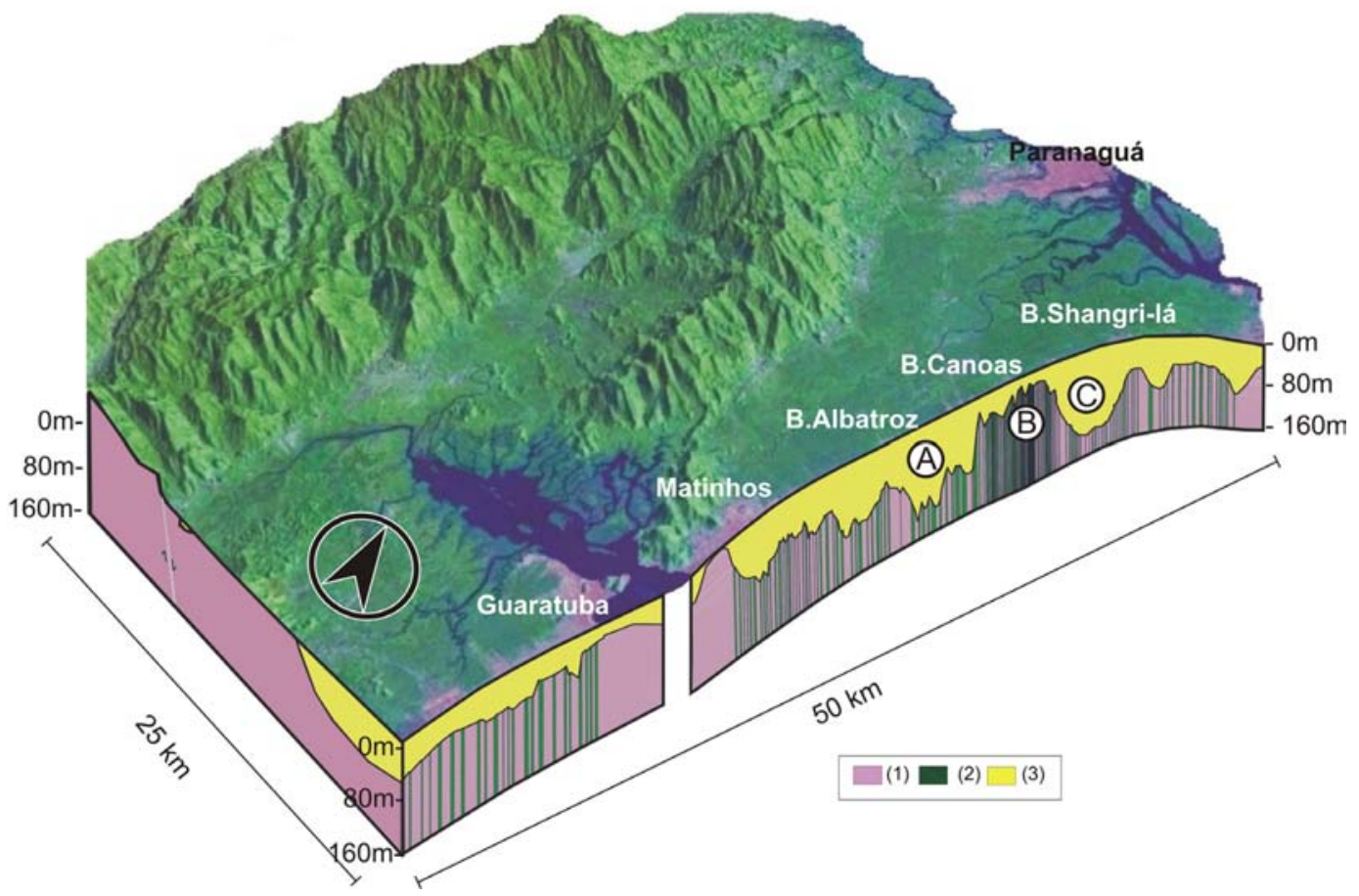

Figura 24 - Modelo geológico do Gráben de Paranaguá na área de estudo associado ao MDE. (1) embasamento indiferenciado (lilás); (2) diques (verde); (3) sedimentos indiferenciados (amarelo); (A) Baixo Estrutural de Albatroz; (B) Alto Estrutural de Canoas; (C) Baixo Estrutural de Shangri-lá. 
encerrariam espessuras máximas de sedimentos da ordem de 130 metros (Tab. 2).

A estimativa de extensão crustal alcançada no presente trabalho $(27 \%)$ é superior às obtidas por outros autores (18\% Ferreira et al., 1989 a,b; 12\% - Portela Filho \& Ferreira 2003), os quais se basearam em dados aeromagnéticos, portanto com significativa perda de resolução, como já ressaltado por Ussami et al. (1991). Assim sendo, tal discrepância pode ser explicada pelas considerações anteriores, em adição ao cerrado intervalo de amostragem (25 metros) do levantamento magnético terrestre, o qual é compatível com as espessuras médias reais dos diques (e.g. Marini et al., 1967). A freqüência média de quatro diques/ $\mathrm{km}$ aqui obtida se revelou mais elevada do que a observada por Marini et al. (1967), na região central do APG, a qual oscilou de 2 a 3 diques $/ \mathrm{km}$, excepcionalmente 4 diques $/ \mathrm{km}$.

Finalmente, a utilização de métodos de investigação geofísica em correspondência a dados diretos, permitiu conceber um modelo geológico, com base na modelagem conjunta de dados gravimétricos e magnéticos, supostamente representativo do topo do embasamento e das decorrentes espessuras da cobertura sedimentar da porção continental do Gráben de Paranaguá.

\section{AGRADECIMENTOS}

Os autores agradecem à Minerais do Paraná S.A. (Mineropar) pela cessão dos arquivos cartográficos e geológicos; ao Instituto de Astronomia, Geofísica e Ciências Atmosféricas da Universidade de São Paulo (IAG-USP) pela disponibilização dos dados gravimétricos regionais e ao Laboratório de Geodésia Espacial (LAGE), Departamento de Geomática da Universidade Federal do Paraná (UFPR), pelo apoio nos trabalhos de posicionamento das estações gravimétricas. Os autores também agradecem ao Geólogo Rodoilton Stevanato, ao Engenheiro Cartógrafo Jefferson Ulisses da Cunha e ao aluno de Graduação em Geologia José Augusto Simões Neto (Bolsista PIBIC/CNPq), todos do LPGA/UFPR, pela colaboração durante os trabalhos de aquisição e processamento dos dados. Francisco J.F. Ferreira agradece ao Conselho Nacional de Desenvolvimento Científico e Tecnológico (CNPq) pelo auxílio concedido (processo n 47.0689/2004-8). Finalmente os autores agradecem aos dois revisores da Revista Brasileira de Geofísica, cujas contribuições foram decisivas para 0 aprimoramento do trabalho.

\section{REFERÊNCIAS}

AGOCS WB. 1951. Least-squares residual anomaly determination. Geophysics, 16: 686-696.

ALMEIDA FFM de. 1976. The system of continental rifts bordering the Santos Basin, Brazil. An. Acad. Brasil. Ciênc., 48 (Supl.): 15-26.
ANGULO RJ. 1992. Geologia da planície costeira do Estado do Paraná. Tese de Doutoramento, Universidade de São Paulo, 334 p.

ANGULO RJ. 2004. Mapa do Cenozóico do litoral do Estado do Paraná. Boletim Paranaense de Geociências, 55: 25-42.

BASSINI AM. 1986. Levantamentos sismográficos na região sudeste do Brasil. Dissertação (Mestrado em Geofísica) - Instituto de Astronomia, Geofísica e Ciências Atmosféricas. Universidade de São Paulo, São Paulo, $162 \mathrm{p}$.

BELTRÃO JF, SILVA JBC \& COSTA JC. 1991. Robust polynomial fitting method for regional gravity estimation. Geophysics, 56: 80-89.

BIGARELLA JJ. 1946. Contribuição ao estudo da planície litorânea do Estado do Paraná. Arq. Biol. Tec., 1: 75-111.

BIGARELLA JJ, DOUBEK A \& SALAMUNI R. 1957. Planta geológica provisória da Baía de Guaratuba. Bol. Univ. Par. Geol., 8: 1-6.

FERREIRA FJF. 1982a. Alinhamentos estruturais-magnéticos da região centro-oriental da Bacia do Paraná e seu significado tectônico. In: Bacia do Paraná - Reavaliação da potencialidade e prospectividade em hidrocarbonetos. Consórcio CESP-IPT (Paulipetro), São Paulo, p. 143-166.

FERREIRA FJF. 1982b. Integração de dados aeromagnéticos e geológicos: configuração e evolução tectônica do Arco de Ponta Grossa. Dissertação (Mestrado em Geologia Geral e de Aplicação) - Universidade de São Paulo, São Paulo, 170 p.

FERREIRA FJF, MONMA R, CAMPANHA GAC \& GALLI VL. 1989a. Estimativa dos graus de extensão e afinamento crustais associados ao Lineamento de Guapiara com base em modelagens aeromagnetométricas e gravimétricas. Boletim Especial, Trabalhos Apresentados. Workshop "Diques Máficos Precambrianos do Brasil”, p. 67-75.

FERREIRA FJF, MONMA R, CAMPANHA GAC \& GALLI VL. 1989b. An estimate of the degree of crustal extension and thinning associated with the Guapiara Lineament based on aeromagnetic and gravimetric modelling. Bol. IG-USP, Série Científica, 20: 69-70.

FRANCO AOB. 2006. Termocrologia por traços de fissão em apatitas na região do Arco de Ponta Grossa entre os alinhamentos de Guapiara e São Jerônimo-Curiúva. Dissertação de Mestrado, Instituto de Geociências e Ciências Exatas, Universidade Estadual Paulista, Rio Claro, São Paulo, $123 p$.

LESSA G, ANGULO RJ, GIANNINI PCF \& ARAÚJO AD. 2000. Stratigraphy and Holocene evolution of a regressive barrier in south Brazil. Marine Geology, 165: 87-108.

MARINI OJ, FUCK RA \& TREIN E. 1967. Intrusivas básicas JurássicoCretáceas do Paraná. Boletim Paranaense de Geociências, 26: 85-124.

MINEROPAR. Minerais do Paraná S.A. 2001. Mapa geológico do Estado do Paraná.

PORTELA FILHO CV. 2003. Condicionamento estrutural-magnético do sistema Aqǘfero Serra Geral na região central do Arco de Ponta Grossa 
(Bacia do Paraná) e sua conectividade com o Sistema Aqüífero Guarani. Dissertação de Mestrado, Universidade Federal do Paraná, 128 p.

PORTELA FILHO CV \& FERREIRA FJF. 2003. Estimativas das taxas de extensão crustal da região central do Arco de Ponta Grossa (Bacia do Paraná) com base em modelagens aeromagnéticas. Resumos Expandidos, VIII Congresso Internacional da Sociedade Brasileira de Geofísica, Rio de Janeiro, RJ. CD-ROM.

PORTELA FILHO CV, FERREIRA FJF, RAPOSO MIB \& STRUGALE M. 2005. Estimativa da extensão crustal do Arco de Ponta Grossa com base em modelagens aeromagnéticas na região de Apucarana-PR. Boletim de Resumos Expandidos, X Simpósio Nacional de Estudos Tectônicos, Curitiba-PR, p. 134-136.

RAPOSO MIB. 1992. Paleomagnetismo do enxame de diques do Arco de Ponta Grossa. Tese de Doutoramento, Universidade de São Paulo, 104 p.

RICCOMINI C. 1991. O Rift Continental do Sudeste do Brasil. Tese de Doutoramento, Universidade de São Paulo, 256 p.

RICCOMINI C. 1995. Padrão de fraturamentos do maciço alcalino de Cananéia, Estado de São Paulo: relações com a tectônica mesozóicocenozóica do sudeste do Brasil. Revista Brasileira de Geociências, 25(2): 79-84.

RICCOMINI C, SANT'ANNA LG \& FERRARI AL. 2004. Evolução geológica do Rift Continental do Sudeste do Brasil. In: MANTESSO NETO V, BARTORELLI A, CARNEIRO CDR \& BRITO NEVES BB. (Ed.). Geologia do Continente Sul-Americano: evolução da obra de Fernando Flávio Marques de Almeida. Editora Beca, p. 383-405.

ROSALES MJT. 2004. Integração de dados gravimétricos terrestres e aeromagnéticos e sua aplicação do estudo geológico-estrutural da Faixa Apiaí. Tese de Doutoramento. Instituto de Astronomia, Geofísica e Ciências Atmosféricas, Universidade de São Paulo, 271 p.

SKEELS DC. 1967. What is residual gravity? Geophysics, 32: 872-876.

SOUZA LAP. 1995. A planície costeira Cananéia-Iguape, litoral sul do Estado de São Paulo: um exemplo de utilização de métodos geofísicos no estudo de áreas costeiras. Dissertação de Mestrado, Universidade de São Paulo, 207 p.

SOUZA LAP, TESSLER MG \& GALLI VL. 1996. 0 Gráben de Cananéia. Revista Brasileira de Geociências, 26(3): 139-150.

SOUZA MC. 2005. Estratigrafia e evolução das barreiras holocênicas paranaenses, sul do Brasil. Tese de Doutoramento, Universidade Federal do Paraná, $121 \mathrm{p}$.

SRTM/USGS. 2000. Shuttle Radar Topography Mission. United States Geological Survey. Disponível em: <http://srtm.usgs.gov>. Acesso em: 16 abr. 2006.

STRUGALE M, ROSTIROLLA SP, MANCINI F, PORTELA FILHO CV, FERREIRA FJF \& FREITAS RC. 2007. Structural framework and Mesozoic-Cenozoic evolution of Ponta Grossa Arch, Paraná basin, southern Brazil. Journal of South American Earth Sciences, 24: 203-227.

TALWANI M \& HEIRTZLER JR. 1964. Computation of gravity anomalies caused by two dimensional structures of arbitrary shapes. Geological Sciences, 1(9): 464-480.

TALWANI M, WORZEL JL \& LANDISMAN M. 1959. Rapid gravity computations for two-dimensional bodies with the application to the Mendocino submarine fracture zone. Journal of Geophysics Research, 64: 49-59.

TELFORD WM, GELDART LP, SHERIFF RE \& KEYS DA. 1990. Applied Geophysics, 2nd ed. Cambridge, Cambridge University Press, $770 \mathrm{p}$.

USSAMI N, KOLISNYK A, RAPOSO MIB, FERREIRA FJF, MOLINA EC \& ERNESTO M. 1991. Detectablidade magnética de diques do Arco de Ponta Grossa: um estudo integrado de magnetometria terrestre/aérea e magnetismo de rocha. Revista Brasileira de Geociências, 21(4): 317-327.

ZALÁN PV \& OLIVEIRA JAB. 2005. Origem e evolução estrutural do Sistema de Riftes Cenozóicos do Sudeste do Brasil. Boletim de Geociências da Petrobras, 13(2): 269-300.

\section{NOTAS SOBRE OS AUTORES}

Luís Gustavo de Castro é Geólogo (UFPR-2001) e Mestre em Geologia Ambiental (UFPR-2007). Atualmente trabalha como prestador de serviços em geologia exploratória, geologia ambiental e geoprocessamento.

Francisco José Fonseca Ferreira é Geólogo (UFPE-1970), Especialista em Geofísica Aplicada (UFBA-1974), Mestre e Doutor em Ciências (USP-1982; USP-1991), Pesquisador do CNPq, com atuação profissional na CPRM (1972-1980) e no IPT (1980-1990). Atualmente é Professor Associado do Departamento de Geologia da UFPR, onde ministra disciplinas de geofísica aplicada nos Cursos de Graduação e Pós-Graduação. A partir de 1998 coordena o Laboratório de Pesquisas em Geofísica Aplicada - LPGA/UFPR, onde desenvolve pesquisas multidisciplinares aplicadas ao ambiente, à cartografia geológica e pedológica, à exploração mineral e de águas subterrâneas.

Rodolfo José Angulo é Geólogo (UNS - Argentina-1972), Mestre em Ciências dos Solos (UFPR-1983), Doutor em Geologia Sedimentar (USP-1992), Pesquisador do CNPq. Atualmente é Professor Associado do Departamento de Geologia da UFPR onde ministra as disciplinas Sistemas Deposicionais, Geologia Costeira, Quaternário e Mudanças Globais, Geologia Ambiental e Avaliação de Impactos Ambientais, e Evolução e Dinâmica de Ambientes Costeiros nos cursos de Graduação e Pós-Graduação em Geologia e Oceanografia e no doutorado em Meio Ambiente e Desenvolvimento. Coordena o Laboratório de Estudos Costeiros - LECOST/UFPR e 0S grupos de pesquisa Evolução, Dinâmica e Recursos Costeiros e Dinâmicas Naturais dos Ambientes Costeiros: Apropriação, Usos e Conflitos. Atua nas áreas de Sedimentologia, Geologia do Quaternário, Geologia Costeira e Geologia Ambiental. 